\title{
SYNERGISTIC EFFECTS OF RHIZOBIAL INOCULUM WITH CHEMICAL FERTILIZER ON GROWTH AND YIELD OF WHEAT
}

\author{
SABER, T. D. ${ }^{*}-$ KHURSHEED, M. Q. \\ Department of Biology, College of Education, University of Salahaddin-Erbil, Iraq \\ *Corresponding author \\ e-mail:trifa.saber@su.edu.krd
}

(Received 12 $2^{\text {th }}$ Apr 2019; accepted 22 $2^{\text {nd }}$ May 2019)

\begin{abstract}
The present study was aimed at examining the combined effect of five species of rhizobial inoculation (Control, Bradyrhizobium sp. (Vigna), Rhizobium leguminosarum bv. viciae, Bradyrhizobium Mungbean, Mesorhizobium ciceri, and Rhizobium leguminosarum bv phaseoli) at three levels $\left(120,240,360 \mathrm{~kg}^{-h a^{-1}}\right)$ of NPK on the physiological characteristics, yield components, and leaf chemical content of two wheat species. The results indicated that all physiological characteristics and all nutrient contents of leaf under study, total dry weight of plant at harvest, spike weight, grain number, grain yield, biological yield, and harvest index increased significantly as a result of the interaction between the chemical fertilizer, the biofertilizer, and the wheat species. It was observed that the combination of rhizobial bacteria and wheat species had a positive effect on the physiological characteristics, leaf nutrient contents, and yield components, but not on spike length, spikelet number, and weight of 1000 grains. Our data suggested that a lower level of NPK fertilizer and rhizobial inoculation should be combined in order to achieve the greatest effect on yield components. Also, different types of rhizobial bacteria should be used as biofertilizer in order to improve wheat production.
\end{abstract}

Keywords: physiological characteristics, bacteria, production, leaf, Triticum sp.

\section{Introduction}

As one of the first cultivated plants, wheat is regarded as the most significant cereal because it is a major food supply for human. There are numerous species of wheat. For example, macaroni wheat (Triticum durum) is a tetraploid wheat species which are cultivated in order to fulfill the demands of the pasta market, whereas Triticum aestivum is a hexaploid species that is widely grown throughout the planet (AbouTaleb and Gomaa, 2012). This species (i.e. Triticum aestivum) is one of the most important crops worldwide (Wang et al., 2018). Given the fact that there has been a huge global demand for food as a result of increased world population over the last few decades, a large number of research studies have been aimed at increasing food production so as to meet humanity needs around the world. These diverse researches have included environmental, physiological, agricultural, and genetic studies which all aimed to increased crops productivity (Elghair, 2012).

In order to increase the yields, there has been an increase in the use of mineral fertilizers which are very costly and cause pollution in many ways. Therefore, researchers have always attempted to control such threats by producing alternative substitutes which are more economical, environmentally friendly, and properly improved. In this regard, use of beneficial microbes or plant growth promoting rhizobacteria has been proposed as the best approach to improve crop yield (Adnan et al., 2014). Another widely utilized method to enhance soil fertility and crop productivity is the use of chemical fertilizers which have a negative effect on the complex system of biogeochemical cycles. One of their negative effects, for example, 
is environmental degradation due to runoff and leaching of nutrients, particularly $\mathrm{P}$ and $\mathrm{N}$ (Yildirim et al., 2011). Another method to increase crop productivity is to use biofertilizers which are substances that contains living microorganisms and applied to plant surface, seeds, or soil. Biofertilizers add nutrients by stimulating plant growth through the synthesis of growth promoting substances and through the natural processes of nitrogen fixation, solubilizing phosphorus. By utilizing biofertilizers, it is expected that there will be a remarkable decrease in the use of chemical fertilizer and pesticides. It is stated that natural nutrient cycle of the soil can be restored and the soil organic matter can be built through the microorganisms in biofertilizers (Al-Shamma and Al-Shahwany, 2014). Moreover, soil contains a wide range of microbes that can act in symbiosis or non-symbiosis association with their host plant (Gray and Smith, 2005).

A range of bacterial genera like Rhizobium, Bradyrhizobium, Sinorhizobium, Mesorhizobium, Allorhizobium, and Azorhizobium exist in rhizobia through which a symbiosis can be established with leguminous plants. Special organs that are known as nodules are produced by these genera on the stems and roots of the hosts, leading to a decrease in atmospheric nitrogen that is delivered to the plant (Sessitsch et al., 2002). As plant growth promoting rhizobacteria (PGPR), rhizobia can also be used in non-legumes (Yanni et al., 1997). Moreover, by producing IAA, gibberellins, and cytokinins, it can enhance growth and yield of cereals (Zahir et al., 2010). Moreover, by producing organic acids, it increase the supply of insoluble nutrients such as phosphorus and iron (Fatima et al., 2006), making these nutrients easily available for plant uptake (Biswas et al., 2000). It is widely reported that the growth parameters, yield, components, and chemical constituents in treated plants can be improved through inoculation of such plants with Azospirillum, Azotobacter, Rhizobium, and Pseudomonas in dual or different combinations with organic and mineral fertilizers. According to previous experiments, the best results were obtained by mixing the various inoculations and applying on wheat plants, leading to reduced amount of mineral fertilizers (Mitkees et al., 1996).

The present study was carried out in order to assess the effectiveness of rhizobial bacteria in reducing the use of chemical fertilizer and improving wheat production.

\section{Materials and methods}

\section{Pot experiment}

The experiment was carried out in the Glasshouse of Biology Department, College of Science, University of Salahaddin-Erbil during winter 2016-2017. The experimental plants used in this experiment included wheat (Triticum aestivum) cultivar Hawler2 and (Triticum durum) cultivar Seminto that were obtained from the Agricultural Research Center in Erbil. The experiments were carried out using plastic pots with a depth of $25 \mathrm{~cm}$ and a diameter of $30 \mathrm{~cm}$. Using a $4 \mathrm{~mm}$ pore size sieve, the soil was sieved and then sterilized using formalin $40 \%$ as described by Elia et al. (1987). Each pot was filled with $8 \mathrm{~kg}$ sandy clay loam soil. Table 1 presents some of the chemical and physical properties of the soil before the treatments. A sufficient number of wheat seeds were separated and disinfected with $95 \%$ ethanol for $30 \mathrm{~s}$ and then washed with sterilized distilled water at least 8 times (Etesami et al., 2009). In each pot, 5 seeds were sown at a depth of $3-4 \mathrm{~cm}$ and later thinned to four plants. 
Table 1. Some physical and chemical properties of soil under investigation

\begin{tabular}{c|c|c}
\hline \multicolumn{2}{c|}{ Properties } & Value \\
\hline & Sand & 67.8 \\
Particle size distribution (\%) & Silt & 10.9 \\
& Clay & 21.3 \\
\hline Soil texture & Sandy clay loam \\
$\mathrm{pH}$ & 8.2 \\
Electrical conductivity $\left(\mathrm{dS} . \mathrm{m}^{-1}\right)$ & 0.60 \\
Total nitrogen\% & 0.56 \\
Total phosphorous\% & 0.144 \\
Total potassium\% & 0.056 \\
Calcium\% & 0.253 \\
Iron\% & 0.078 \\
\hline
\end{tabular}

\section{Isolation of Rhizobial sp}

Five strains of rhizobia including Bradyrhizobium sp. (Vigna), Rhizobium leguminosarum bv. viciae, Bradyrhizobium Mungbean, Mesorhizobium ciceri and Rhizobium leguminosarum bv. phaseoli were isolated from Vigna unguiculata, Vicia faba, Vigna radiata L., Cicer arietinum L., and Phaseoulus vulgasrous root nodules, respectively which were growing for 2-3 months under field conditions at a different area of Erbil city. Afterwards, the host plants which had some non-rhizopheric soil on them were uprooted, and they were placed in polythene bags and taken to the laboratory. By shaking the uprooted plants, their non-rhizospheric soil was removed. Moreover, by dipping and shaking them in water, their rhizospheric soil was removed. The nodules were separated from the roots with a sterilized razor blade, and each of them was placed in a separate Petri plates. The surface of the nodules was disinfected by dipping them in ethanol (95\%) for $20 \mathrm{~s}$ and then in $\mathrm{HgCl}_{2}(0.2 \%)$ solution for 3 min followed by washing them with sterilized distilled water 6 times. Using a sterilized glass rod, the surfacedisinfected nodules of each host were crushed in a sterilized test tube containing sterilized distilled water. The obtained suspension was used to inoculate Petri plates that contained autoclaved and solidified yeast extract mannitol (YEM) media which was then incubated at $28 \pm 1{ }^{\circ} \mathrm{C}$ for bacterial growth (Mehboob et al., 2011).

\section{Preparation of inoculums}

In order to complete the preparation of inoculum, the selected isolates of rhizobia were grown in $250 \mathrm{~mL}$ conical flask containing $100 \mathrm{~mL}$ YEM broth by incubating at $28 \pm 1{ }^{\circ} \mathrm{C}$ in an orbital shaking incubator at $100 \mathrm{rpm}$ for 3 days. In order to obtain uniform cell density (i.e. $10^{8}$ to $10^{9} \mathrm{CFU} \mathrm{mL} \mathrm{mL}^{-1}$ ), dilution method was employed in so as to record an optical density of 0.5 at a wavelength of $535 \mathrm{~nm}$ (Mehboob et al., 2011). Inoculation of $10 \mathrm{ml}\left(10^{8}-10^{9}\right.$ CFU.mL $\left.{ }^{-1}\right)$ per seedling was done at the base of the plant ten days after germination.

\section{Experimental design and treatment}

The current experiment included 6 treatments of rhizobial inoculums (i.e. Control, Bradyrhizobium sp. (Vigna), Rhizobium leguminosarum bv. viciae, Bradyrhizobium 
Mungbean, Mesorhizobium ciceri, and Rhizobium leguminosarum bv. phaseoli) and 3 levels of NPK (20:20:20) fertilizers (120, 240 and $\left.360 \mathrm{~kg} \cdot \mathrm{ha}^{-1}\right)$, making a total of 36 treatments per replication. The experiment was carried out using a factorial complete randomized design (Factorial C.R.D.) with 3 replications. The comparisons between means were made using Tukey test at significant level of $5 \%$ for field experiment parameters and $1 \%$ for laboratory parameters. SPSS version 16 was used for data analysis.

\section{Experimental parameters}

\section{Physiological parameters}

The spectrophotometric method as described by Lichtenthaler (1987) was employed to measure chlorophyll a, chlorophyll $b$, and carotenoid based on the flag leaf samples that were collected at flowering stage during the growing period.

$$
\begin{aligned}
& \text { Chlorophyll } a=(13.36 \times \text { A664.2) }-(5.19 \times A 648.6) \\
& \text { Chlorophyll } b=(27.43 \times \text { A648.6) }-(8.12 \times A 664.2) \\
& \text { Total Chlorophyll }=\text { Chlorophy } a+\text { Chlorophy } b
\end{aligned}
$$$$
\text { Carotenoid }=\{(1000 \times A 470)-(2.13 \times \text { Ch } a)-(97.64 \times C h b)\} / 209
$$

In order to determine the membrane stability index (MSI), the method proposed by Premachandra et al. (1991) was utilized.

$$
M S I=[1-(C 1 / C 2)] \times 100
$$

\section{Biochemical contents}

Dried leaves at flowering stage were ground by an electrical grinder. Afterwards, $0.3 \mathrm{~g}$ of the ground samples was digested by adding $10 \mathrm{ml} \mathrm{H}_{2} \mathrm{O}_{2}$ and $10 \mathrm{ml}$ concentrated $\mathrm{H}_{2} \mathrm{SO}_{4}$, and they were heated. After that, Kjeldahl method was employed to determine the total nitrogen, spectrophotometer method was used to estimate the total phosphorus, atomic absorption method was utilized to estimate the total calcium and iron, and flamephotometer method as described by Ryan et al. (2001) was used to determine the total potassium determined. Moreover, by multiplying the value of total nitrogen by 5.75, the total protein was calculated (Dalaly and Al-Hakim, 1987). Also, the Anthron method (Sadasivam, 1996) was utilized to determine the total soluble carbohydrate.

\section{Yield components}

At harvest, main spike length (cm), number of grains.plant ${ }^{-1}$, weight of spikes.plant ${ }^{-1}$, grain yield $\left(\mathrm{kg}\right.$ ha $\left.{ }^{-1}\right)$, biological yield $\left(\mathrm{kg} \mathrm{ha}^{-1}\right)$, number of spikelets.spike ${ }^{-1}$, harvest index (\%), weight of 1000 grains (g), and increase grain yield (\%) were estimated. The following formula proposed by Ye et al. (2005) was employed to determine the increased grain yield. 


\section{Increase grain yield $\%=(($ Grain yield of fertilized pot - Grain yield of control)/Grain yield of control) $\times 100$}

\section{Results}

\section{Physiological parameters}

According to the data presented in Table 2, it was detected that soil application of B3 led to the highest levels of chlorophyll a, chlorophyll b, total chlorophyll, and carotenoid, while the highest value of cell membrane stability was obtained by utilizing B5.

Table 2. Effects of different species of rhizobial bacteria on some physiological characteristics

\begin{tabular}{c|c|c|c|c|c}
\hline $\begin{array}{c}\text { Bacterial } \\
\text { species }\end{array}$ & $\begin{array}{c}\text { Chlorophyll a } \\
\left(\mathbf{m g . g}^{-1}\right)\end{array}$ & $\begin{array}{c}\text { Chlorophyll b } \\
\left(\mathbf{m g . g}^{-1}\right)\end{array}$ & $\begin{array}{c}\text { Total } \\
\text { chlorophyll } \\
\left(\mathbf{m g . g}^{-1}\right)\end{array}$ & $\begin{array}{c}\text { Carotenoid } \\
\left(\mathbf{m g . g}^{-1}\right)\end{array}$ & $\begin{array}{c}\text { Cell membrane } \\
\text { stability \% }\end{array}$ \\
\hline Control & 0.950 & 0.609 & 1.559 & 0.422 & 88.557 \\
B1 & 1.326 & 1.061 & 2.387 & 0.666 & 93.079 \\
B2 & 1.426 & 1.149 & 2.574 & 0.696 & 93.401 \\
B3 & 1.438 & 1.199 & 2.638 & 0.725 & 93.105 \\
B4 & 1.394 & 0.961 & 2.356 & 0.675 & 94.083 \\
B5 & 1.343 & 1.130 & 2.473 & 0.671 & 94.248 \\
\hline Tukey 0.01 & 0.125 & 0.163 & 0.253 & 0.105 & 0.133 \\
\hline
\end{tabular}

B1: Bradyrhizobium sp. (Vigna), B2: Rhizobium leguminosarum bv. viciae, B3: Bradyrhizobium Mungbean, B4: Mesorhizobium ciceri, B5: Rhizobium leguminosarum bv phaseoli

The results also indicated that the highest values of chlorophyll a and cell membrane stability were obtained by adding $360 \mathrm{~kg} \cdot \mathrm{ha}^{-1}$ of NPK (see Table 3). On the other hand, using $240 \mathrm{~kg} \cdot \mathrm{ha}^{-1}$ of NPK led to obtaining the maximum value of total chlorophyll and carotenoid.

Table 3. Effects of different levels of chemical fertilizers on some physiological characteristic

\begin{tabular}{|c|c|c|c|c|c|}
\hline $\begin{array}{l}\text { Chemical } \\
\text { fertilizer } \\
\left(\mathrm{kg}^{-} \mathrm{ha}^{-1}\right)\end{array}$ & $\begin{array}{c}\text { Chlorophyll a } \\
\text { (mg.g) }^{-1}\end{array}$ & $\begin{array}{c}\text { Chlorophyll b } \\
\left(\text { mg.g }^{-1}\right)\end{array}$ & $\begin{array}{c}\text { Total } \\
\text { chlorophyll } \\
\left(\text { mg.g }^{-1}\right)\end{array}$ & $\begin{array}{c}\text { Carotenoid } \\
\left(\mathrm{mg}^{-g^{-1}}\right)\end{array}$ & $\begin{array}{c}\text { Cell membrane } \\
\text { stability \% }\end{array}$ \\
\hline NPK1 & 1.216 & 0.9706 & 2.187 & 0.589 & 92.433 \\
\hline NPK2 & 1.353 & 1.052 & 2.405 & 0.671 & 92.700 \\
\hline NPK3 & 1.370 & 1.032 & 2.402 & 0.668 & 93.103 \\
\hline Tukey 0.01 & 0.075 & n.s. & 0.153 & 0.063 & 0.08 \\
\hline
\end{tabular}

NPK1 $=120 \mathrm{~kg} \cdot \mathrm{ha}^{-1}, \mathrm{NPK} 2=240 \mathrm{~kg} \cdot \mathrm{ha}^{-1}, \mathrm{NPK} 3=360 \mathrm{~kg} \cdot \mathrm{ha}^{-1}$

The results presented in Table 4 revealed that Triticum durum significantly surpassed Triticum aestivum regarding the total chlorophyll and cell membrane stability, while wheat species had no effect on chlorophyll a, chlorophyll b, and carotenoid. 
Table 4. Effects of wheat species on some physiological characteristics

\begin{tabular}{c|c|c|c|c|c}
\hline Wheat species & $\begin{array}{c}\text { Chlorophyll a } \\
\text { (mg.g) }^{-\mathbf{1}}\end{array}$ & $\begin{array}{c}\text { Chlorophyll b } \\
\left.\text { (mg.g }^{-1}\right)\end{array}$ & $\begin{array}{c}\text { Total } \\
\text { chlorophyll } \\
\text { (mg.g }^{-1}\end{array}$ & $\begin{array}{c}\text { Carotenoid } \\
\text { (mg.g-1) }^{-1}\end{array}$ & $\begin{array}{c}\text { Cell membrane } \\
\text { stability \% }\end{array}$ \\
\hline T. aestivum & 1.289 & 0.990 & 2.279 & 0.637 & 91.879 \\
T. durum & 1.3370 & 1.0464 & 2.383 & 0.6480 & 93.612 \\
Tukey 0.01 & n.s. & n.s. & 0.087 & n.s. & 0.057 \\
\hline
\end{tabular}

As indicated in Table 5, Rhizobium inoculation resulted in significant increase in physiological parameters in both wheat species. The highest values of chlorophyll a and carotenoid were respectively 1.501 and $0.750 \mathrm{mg}^{-\mathrm{g}^{-1}}$ that were recorded in B2 of Triticum durum, while highest value of chlorophyll b was $1.258 \mathrm{mg} \cdot \mathrm{g}^{-1}$ and the total chlorophyll was $2.737 \mathrm{mg}^{-1}{ }^{-1}$, which were recorded in B3 of Triticum durum. The results presented in Table 5 also revealed that the highest value of cell membrane stability was $94.417 \%$ that was recorded in B1 of Triticum durum.

Table 5. Interaction effects of wheat species and rhizobial bacteria on some physiological characteristics

\begin{tabular}{|c|c|c|c|c|c|c|}
\hline Wheat species & $\begin{array}{c}\text { Bacterial } \\
\text { species }\end{array}$ & $\begin{array}{c}\text { Chlorophyll a } \\
(\mathrm{mg} \cdot \mathrm{g})^{-1}\end{array}$ & $\begin{array}{c}\text { Chlorophyll b } \\
\left(\mathrm{mg.g}^{-1}\right)\end{array}$ & $\begin{array}{c}\text { Total } \\
\text { chlorophyll } \\
\left(\mathrm{mg}^{\left.-g^{-1}\right)}\right. \\
\end{array}$ & $\begin{array}{c}\text { Carotenoid } \\
\left(\mathrm{mg}^{-\mathrm{g}^{-1}}\right)\end{array}$ & $\begin{array}{c}\text { Cell } \\
\text { membrane } \\
\text { stability \% } \\
\end{array}$ \\
\hline \multirow{6}{*}{ T. aestivum } & Control & 0.928 & 0.596 & 1.523 & 0.452 & 86.529 \\
\hline & B1 & 1.204 & 0.980 & 2.184 & 0.631 & 91.740 \\
\hline & B2 & 1.350 & 1.091 & 2.441 & 0.643 & 92.735 \\
\hline & B3 & 1.397 & 1.142 & 2.539 & 0.717 & 92.075 \\
\hline & B4 & 1.445 & 0.965 & 2.410 & 0.709 & 93.916 \\
\hline & B5 & 1.408 & 1.169 & 2.577 & 0.672 & 94.281 \\
\hline \multirow{6}{*}{ T. durum } & Control & 0.972 & 0.624 & 1.595 & 0.391 & 90.586 \\
\hline & B1 & 1.448 & 1.142 & 2.590 & 0.702 & 94.417 \\
\hline & $\mathrm{B} 2$ & 1.501 & 1.207 & 2.708 & 0.750 & 94.067 \\
\hline & B3 & 1.480 & 1.258 & 2.737 & 0.734 & 94.136 \\
\hline & B4 & 1.344 & 0.958 & 2.302 & 0.642 & 94.250 \\
\hline & B5 & 1.278 & 1.091 & 2.368 & 0.670 & 94.215 \\
\hline \multicolumn{2}{|c|}{ Tukey 0.01} & 0.199 & 0.26 & 0.405 & 0.168 & 0.212 \\
\hline
\end{tabular}

B1: Bradyrhizobium sp. (Vigna), B2: Rhizobium leguminosarum bv. viciae, B3: Bradyrhizobium Mungbean, B4: Mesorhizobium ciceri, B5: Rhizobium leguminosarum bv phaseoli

According to the results presented in Table 6, different levels of NPK fertilizer led to significant increase in photosynthetic pigments and cell membrane stability of the two wheat species. The highest value of all photosynthetic pigments was recorded at $240 \mathrm{~kg} \cdot \mathrm{ha}^{-1}$ of Triticum durum, while using $360 \mathrm{~kg} \cdot \mathrm{ha}^{-1}$ of Triticum durum resulted in the highest value of cell membrane stability.

The data presented in Table 7 show how photosynthetic pigments and cell membrane stability were influenced by different combinations of different levels of NPK fertilizer and different species of rhizobial bacteria. As indicated, using $240 \mathrm{~kg} . \mathrm{ha}^{-1}$ with B4 led 
to highly significant increases in chlorophyll a, total chlorophyll, and carotenoid. However, the highest value of chlorophyll b was obtained as result of using $240 \mathrm{~kg}^{-\mathrm{ha}^{-1}}$ with B5. Moreover, using $360 \mathrm{~kg} \cdot \mathrm{ha}^{-1}$ of NPK with B5 led to the highest cell membrane stability.

Table 6. Interaction effect of wheat species and chemical fertilizers on some physiological characteristics

\begin{tabular}{|c|c|c|c|c|c|c|}
\hline Wheat species & $\begin{array}{l}\text { Chemical } \\
\text { fertilizer } \\
\left(\mathrm{kg.ha}^{-1}\right)\end{array}$ & $\begin{array}{c}\text { Chlorophyll a } \\
{\text { (mg.g })^{-1}}^{-1}\end{array}$ & $\begin{array}{c}\text { Chlorophyll b } \\
\left(\text { mg.g }^{-1}\right)\end{array}$ & $\begin{array}{c}\text { Total } \\
\text { chlorophyll } \\
\left(\mathrm{mg.g}^{-1}\right)\end{array}$ & $\begin{array}{c}\text { Carotenoid } \\
\left(\mathrm{mg}^{-1} \mathrm{~g}^{-1}\right)\end{array}$ & $\begin{array}{c}\text { Cell } \\
\text { membrane } \\
\text { stability \% }\end{array}$ \\
\hline \multirow{3}{*}{ T. aestivum } & NPK1 & 1.227 & 0.996 & 2.224 & 0.605 & 91.483 \\
\hline & NPK2 & 1.242 & 0.918 & 2.160 & 0.624 & 91.988 \\
\hline & NPK3 & 1.396 & 1.056 & 2.453 & 0.683 & 92.167 \\
\hline \multirow{3}{*}{ T. durum } & NPK1 & 1.205 & 0.945 & 2.150 & 0.573 & 93.384 \\
\hline & NPK2 & 1.463 & 1.187 & 2.650 & 0.718 & 93.412 \\
\hline & NPK3 & 1.343 & 1.008 & 2.350 & 0.652 & 94.039 \\
\hline \multicolumn{2}{|c|}{ Tukey 0.01} & 0.125 & 0.163 & 0.253 & 0.105 & 0.133 \\
\hline
\end{tabular}

NPK1 $=120 \mathrm{~kg} \cdot \mathrm{ha}^{-1}, \mathrm{NPK} 2=240 \mathrm{~kg} \cdot \mathrm{ha}^{-1}, \mathrm{NPK} 3=360 \mathrm{~kg} \cdot \mathrm{ha}^{-1}$

Table 7. Interaction effect of chemical fertilizer and rhizobial bacteria on some physiological characteristics

\begin{tabular}{|c|c|c|c|c|c|c|}
\hline $\begin{array}{l}\text { Chemical } \\
\text { fertilizer } \\
\left(\text { kg.ha }^{-1}\right)\end{array}$ & $\begin{array}{c}\text { Bacterial } \\
\text { species }\end{array}$ & $\begin{array}{c}\text { Chlorophyll a } \\
\text { (mg.g) }^{-1}\end{array}$ & $\underset{\left(\mathrm{mg.g}^{-1}\right)}{\text { Chlorophyll b }}$ & $\begin{array}{c}\text { Total } \\
\text { chlorophyll } \\
(\text { mg.g-1) }\end{array}$ & $\begin{array}{c}\text { Carotenoid } \\
\left(\mathrm{mg}^{-1} \mathrm{~g}^{-1}\right)\end{array}$ & \begin{tabular}{|c|} 
Cell \\
membrane \\
stability \%
\end{tabular} \\
\hline \multirow{6}{*}{ NPK1 } & Control & 0.931 & 0.627 & 1.558 & 0.430 & 87.755 \\
\hline & B1 & 1.252 & 0.978 & 2.230 & 0.607 & 93.996 \\
\hline & B2 & 1.344 & 1.204 & 2.547 & 0.669 & 92.720 \\
\hline & B3 & 1.318 & 1.106 & 2.423 & 0.658 & 91.919 \\
\hline & B4 & 1.184 & 0.863 & 2.046 & 0.553 & 94.155 \\
\hline & B5 & 1.269 & 1.047 & 2.316 & 0.616 & 94.056 \\
\hline \multirow{6}{*}{ NPK2 } & Control & 0.898 & 0.495 & 1.393 & 0.395 & 87.843 \\
\hline & B1 & 1.290 & 0.977 & 2.267 & 0.677 & 92.460 \\
\hline & B2 & 1.427 & 1.094 & 2.520 & 0.696 & 93.486 \\
\hline & B3 & 1.475 & 1.252 & 2.727 & 0.773 & 94.135 \\
\hline & B4 & 1.580 & 1.206 & 2.786 & 0.778 & 94.005 \\
\hline & B5 & 1.445 & 1.291 & 2.736 & 0.709 & 94.273 \\
\hline \multirow{6}{*}{ NPK3 } & Control & 1.019 & 0.706 & 1.726 & 0.439 & 90.075 \\
\hline & B1 & 1.436 & 1.229 & 2.665 & 0.715 & 92.780 \\
\hline & B2 & 1.506 & 1.148 & 2.655 & 0.724 & 93.998 \\
\hline & B3 & 1.522 & 1.242 & 2.764 & 0.745 & 93.262 \\
\hline & B4 & 1.419 & 0.816 & 2.235 & 0.695 & 94.089 \\
\hline & B5 & 1.315 & 1.051 & 2.366 & 0.687 & 94.415 \\
\hline
\end{tabular}

B1: Bradyrhizobium sp. (Vigna), B2: Rhizobium leguminosarum bv. viciae, B3: Bradyrhizobium Mungbean, B4: Mesorhizobium ciceri, B5: Rhizobium leguminosarum bv phaseoli. NPK1 $=120 \mathrm{~kg} \cdot \mathrm{ha}^{-1}$, NPK2 $=240 \mathrm{~kg} \cdot \mathrm{ha}^{-1}, \mathrm{NPK} 3=360 \mathrm{~kg} \cdot \mathrm{ha}^{-1}$ 
Leaf photosynthetic pigments and cell membrane stability increased significantly in both wheat species as a result of Rhizobium inoculation and chemical fertilizer treatments (see Table 8). Triticum durum with $240 \mathrm{~kg} \cdot \mathrm{ha}^{-1}$ of NPK combined with B2 surpassed other interactions and resulted in the highest chlorophyll a and total chlorophyll. Furthermore, Triticum durum with $240 \mathrm{~kg} \cdot \mathrm{ha}^{-1}$ of NPK integrated with B5 and B4 led to the maximum chlorophyll $\mathrm{b}$ and carotenoid pigments, respectively, while adding $360 \mathrm{~kg} \cdot \mathrm{ha}^{-1}$ of NPK with B1 in Triticum durum brought about the highest value of cell membrane stability.

Table 8. Interaction effect of wheat species, chemical fertilizer and rhizobial bacteria on some physiological characteristics

\begin{tabular}{|c|c|c|c|c|c|c|c|}
\hline Wheat species & $\begin{array}{l}\text { Chemical } \\
\text { fertilizer } \\
\left(\mathrm{kg}^{-h^{-1}}\right)\end{array}$ & $\begin{array}{l}\text { Bacterial } \\
\text { species }\end{array}$ & $\begin{array}{c}\text { Chlorophyll a } \\
\quad(\mathrm{mg} . \mathrm{g})^{-1}\end{array}$ & $\begin{array}{c}\text { Chlorophyll b } \\
\left(\mathrm{mg}^{-g^{-1}}\right)\end{array}$ & $\begin{array}{c}\text { Total } \\
\text { chlorophyll } \\
\left(\mathrm{mg}^{-1}\right)\end{array}$ & $\begin{array}{c}\text { Carotenoid } \\
\left(\mathrm{mg}^{-\mathrm{g}^{-1}}\right)\end{array}$ & $\begin{array}{c}\text { Cell } \\
\text { membrane } \\
\text { stability \% } \\
\end{array}$ \\
\hline \multirow{18}{*}{ T. aestivum } & \multirow{6}{*}{ NPK1 } & Control & 0.814 & 0.615 & 1.430 & 0.357 & 86.978 \\
\hline & & B1 & 1.206 & 1.009 & 2.214 & 0.637 & 93.604 \\
\hline & & B2 & 1.442 & 1.286 & 2.729 & 0.712 & 90.955 \\
\hline & & B3 & 1.255 & 0.991 & 2.246 & 0.633 & 89.425 \\
\hline & & B4 & 1.258 & 0.935 & 2.193 & 0.630 & 93.875 \\
\hline & & B5 & 1.388 & 1.141 & 2.530 & 0.659 & 94.058 \\
\hline & \multirow{6}{*}{ NPK2 } & Control & 0.922 & 0.423 & 1.345 & 0.461 & 85.687 \\
\hline & & B1 & 1.047 & 0.732 & 1.779 & 0.599 & 90.663 \\
\hline & & B2 & 1.195 & 0.828 & 2.023 & 0.575 & 93.056 \\
\hline & & B3 & 1.444 & 1.198 & 2.642 & 0.767 & 94.275 \\
\hline & & B4 & 1.511 & 1.194 & 2.705 & 0.733 & 93.875 \\
\hline & & B5 & 1.335 & 1.134 & 2.469 & 0.610 & 94.375 \\
\hline & \multirow{6}{*}{ NPK3 } & Control & 1.047 & 0.748 & 1.795 & 0.538 & 86.923 \\
\hline & & B1 & 1.359 & 1.201 & 2.560 & 0.658 & 90.955 \\
\hline & & B2 & 1.413 & 1.157 & 2.570 & 0.642 & 94.195 \\
\hline & & B3 & 1.492 & 1.236 & 2.729 & 0.749 & 92.524 \\
\hline & & B4 & 1.566 & 0.766 & 2.331 & 0.764 & 93.998 \\
\hline & & B5 & 1.501 & 1.231 & 2.732 & 0.749 & 94.410 \\
\hline \multirow{18}{*}{ T. durum } & \multirow{6}{*}{ NPK1 } & Control & 1.049 & 0.639 & 1.687 & 0.504 & 88.531 \\
\hline & & $\mathrm{B} 1$ & 1.299 & 0.947 & 2.246 & 0.577 & 94.389 \\
\hline & & B2 & 1.245 & 1.121 & 2.366 & 0.625 & 94.486 \\
\hline & & B3 & 1.381 & 1.220 & 2.601 & 0.683 & 94.413 \\
\hline & & B4 & 1.109 & 0.790 & 1.899 & 0.475 & 94.435 \\
\hline & & B5 & 1.149 & 0.953 & 2.102 & 0.574 & 94.053 \\
\hline & \multirow{6}{*}{ NPK2 } & Control & 0.874 & 0.568 & 1.442 & 0.329 & 89.999 \\
\hline & & B1 & 1.534 & 1.221 & 2.755 & 0.755 & 94.258 \\
\hline & & B2 & 1.658 & 1.359 & 3.017 & 0.817 & 93.915 \\
\hline & & B3 & 1.507 & 1.305 & 2.812 & 0.778 & 93.996 \\
\hline & & B4 & 1.649 & 1.219 & 2.868 & 0.823 & 94.135 \\
\hline & & B5 & 1.555 & 1.448 & 3.003 & 0.809 & 94.170 \\
\hline & \multirow{6}{*}{ NPK3 } & Control & 0.992 & 0.665 & 1.656 & 0.341 & 93.228 \\
\hline & & B1 & 1.513 & 1.257 & 2.769 & 0.773 & 94.605 \\
\hline & & B2 & 1.600 & 1.140 & 2.739 & 0.807 & 93.800 \\
\hline & & B3 & 1.552 & 1.248 & 2.799 & 0.741 & 94.000 \\
\hline & & B4 & 1.272 & 0.866 & 2.138 & 0.626 & 94.180 \\
\hline & & B5 & 1.128 & 0.871 & 1.999 & 0.626 & 94.421 \\
\hline \multicolumn{3}{|c|}{ Tukey0.01 } & 0.403 & 0.528 & 0.821 & 0.341 & 0.431 \\
\hline
\end{tabular}

B1: Bradyrhizobium sp. (Vigna), B2: Rhizobium leguminosarum bv. viciae, B3: Bradyrhizobium Mungbean, B4: Mesorhizobium ciceri, B5: Rhizobium leguminosarum bv phaseoli. NPK1 $=120 \mathrm{~kg} \cdot \mathrm{ha}^{-1}$, NPK2 $=240 \mathrm{~kg} \cdot \mathrm{ha}^{-1}$, $\mathrm{NPK} 3=360 \mathrm{~kg} \cdot \mathrm{ha}^{-1}$ 


\section{Biochemical contents}

The results presented in Table 9 demonstrate that the highest values of nitrogen, iron, and protein were recorded by adding B3. Also, phosphorus and carbohydrate reached their highest values as a result of adding B5. Moreover, the maximum values of potassium and calcium were recorded by adding B1 and B4, respectively.

In was also observed that the highest values of nitrogen, phosphorus, iron, and protein were obtained as a result of using $360 \mathrm{~kg}^{-h^{-1}}$ of NPK (see Table 10). Furthermore, adding $120 \mathrm{~kg} \cdot \mathrm{ha}^{-1}$ of NPK resulted in the greatest potassium content of leaves. Also, $240 \mathrm{~kg} \cdot \mathrm{ha}^{-1}$ of NPK brought about the highest values of calcium and carbohydrate.

According to the data presented in Table 11, Triticum durum surpassed Triticum aestivum significantly in all leaf nutrient contents under study except potassium and calcium which were better in Triticum aestivum than Triticum durum.

Table 9. Effects of different species of rhizobial bacteria on some nutrient content of leaves

\begin{tabular}{c|c|c|c|c|c|c|c}
\hline $\begin{array}{c}\text { Bacterial } \\
\text { species }\end{array}$ & $\begin{array}{c}\text { Protein } \\
\text { mg.g }^{-1}\end{array}$ & $\begin{array}{c}\text { Carbohydrate } \\
\text { mg.g }^{-1}\end{array}$ & $\begin{array}{c}\text { Nitrogen } \\
\text { mg.kg-1 }^{-1}\end{array}$ & $\begin{array}{c}\text { Phosphorus } \\
\text { mg.kg-1 }^{-1}\end{array}$ & $\begin{array}{c}\text { Potassium } \\
\text { mg.kg-1 }^{-1}\end{array}$ & $\begin{array}{c}\text { Calcium } \\
\text { mg.kg-1 }^{-1}\end{array}$ & $\begin{array}{c}\text { Iron } \\
\text { mg.kg }^{-1}\end{array}$ \\
\hline Control & 182.44 & 250.47 & 34064.04 & 2254.53 & 8404.92 & 7443.14 & 121.62 \\
B1 & 240.96 & 308.69 & 43479.46 & 2838.69 & 10481.95 & 8158.36 & 178.22 \\
B2 & 250.70 & 300.24 & 44044.08 & 2569.27 & 10164.06 & 8175.40 & 191.88 \\
B3 & 258.79 & 317.42 & 47026.08 & 3104.00 & 9836.24 & 8142.41 & 217.45 \\
B4 & 232.19 & 324.36 & 40763.83 & 2724.08 & 10350.04 & 8287.79 & 183.37 \\
B5 & 221.68 & 327.73 & 41212.83 & 3818.69 & 9890.59 & 8050.33 & 169.54 \\
\hline Tukey 0.01 & 2.24 & 0.58 & 389.437 & 9.981 & 125.046 & 103.398 & 3.338 \\
\hline
\end{tabular}

B1: Bradyrhizobium sp. (Vigna), B2: Rhizobium leguminosarum bv. viciae, B3: Bradyrhizobium Mungbean, B4: Mesorhizobium ciceri, B5: Rhizobium leguminosarum bv phaseoli

Table 10. Effects of different levels of chemical fertilizer on some nutrient content of leaves

\begin{tabular}{c|c|c|c|c|c|c|c}
\hline $\begin{array}{c}\text { Chemical } \\
\text { fertilizer } \\
\text { (kg.ha-1 }^{-1}\end{array}$ & $\begin{array}{c}\text { Protein } \\
\text { mg.g }^{-1}\end{array}$ & $\begin{array}{c}\text { Carbohydrate } \\
\text { mg.g.-1 }^{-1}\end{array}$ & $\begin{array}{c}\text { Nitrogen } \\
\text { mg.kg-1 }^{-1}\end{array}$ & $\begin{array}{c}\text { Phosphorus } \\
\text { mg.kg-1 }\end{array}$ & $\begin{array}{c}\text { Potassium } \\
\text { mg.kg-1 }^{-1}\end{array}$ & $\begin{array}{c}\text { Calcium } \\
\text { mg.kg-1 }^{-1}\end{array}$ & $\begin{array}{c}\text { Iron } \\
\text { mg.kg-1 }^{-1}\end{array}$ \\
\hline NPK1 & 219.93 & 310.46 & 38248.73 & 2748.11 & 9968.80 & 7832.05 & 178.94 \\
NPK2 & 236.26 & 312.80 & 41087.88 & 2791.14 & 9792.77 & 8208.84 & 165.82 \\
NPK3 & 264.26 & 291.19 & 45958.54 & 3115.39 & 9802.33 & 8087.83 & 186.27 \\
\hline Tukey 0.01 & 1.35 & 0.35 & 234.783 & 6.017 & 75.388 & 62.336 & 2.012 \\
\hline
\end{tabular}

NPK1 $=120 \mathrm{~kg} \cdot \mathrm{ha}^{-1}, \mathrm{NPK} 2=240 \mathrm{~kg} \cdot \mathrm{ha}^{-1}, \mathrm{NPK} 3=360 \mathrm{~kg} \cdot \mathrm{ha}^{-1}$

Table 11. Effect of wheat species on some nutrient content of leaves

\begin{tabular}{c|c|c|c|c|c|c|c}
\hline Wheat species & $\begin{array}{c}\text { Protein } \\
\text { mg.g }^{-1}\end{array}$ & $\begin{array}{c}\text { Carbohydrate } \\
\text { mg.g.-1 }^{-1}\end{array}$ & $\begin{array}{c}\text { Nitrogen } \\
\text { mg.kg-1 }^{-1}\end{array}$ & $\begin{array}{c}\text { Phosphorus } \\
\text { mg.kg }^{-1}\end{array}$ & $\begin{array}{c}\text { Potassium } \\
\text { mg.kg }^{-1}\end{array}$ & $\begin{array}{c}\text { Calcium } \\
\text { mg.kg }^{-1}\end{array}$ & $\begin{array}{c}\text { Iron } \\
\text { mg.kg-1 }^{-1}\end{array}$ \\
\hline T. aestivum & 230.17 & 293.05 & 40029.07 & 2750.18 & 10045.62 & 8248.84 & 168.64 \\
T. durum & 250.13 & 316.58 & 43501.04 & 3019.57 & 9663.65 & 7836.98 & 185.39 \\
\hline Tukey 0.01 & 0.96 & 0.25 & 167.715 & 4.299 & 53.852 & 44.529 & 1.437 \\
\hline
\end{tabular}


It was also observed that the nutrient contents of the leaves in both wheat species increased significantly as a result of different species of Rhizobial inoculation compared with the control species (see Table 12). The highest values of $\mathrm{N}\left(50079.67 \mathrm{mg} \cdot \mathrm{kg}^{-1}\right), \mathrm{Fe}$ (263.34 mg.kg $\left.{ }^{-1}\right)$, protein $\left(287.96 \mathrm{mg} . \mathrm{g}^{-1}\right)$, and carbohydrate $\left(356.79 \mathrm{mg} . \mathrm{g}^{-1}\right)$ were observed in B3 of Triticum durum, while the highest values of P (4350.08 mg. $\mathrm{kg}^{-1}$ ), K (10555.82 mg. $\left.\mathrm{kg}^{-1}\right)$, and Ca $\left(8841.02 \mathrm{mg} \cdot \mathrm{kg}^{-1}\right)$ were respectively recorded in B5 of Triticum durum, B1 of Triticum aestivum, B4 of Triticum aestivum.

Table 12. Interaction effect of wheat species and rhizobial species on some nutrient content of leaves

\begin{tabular}{|c|c|c|c|c|c|c|c|c|}
\hline $\begin{array}{l}\text { Wheat } \\
\text { species }\end{array}$ & $\begin{array}{c}\text { Bacterial } \\
\text { species }\end{array}$ & $\begin{array}{c}\text { Protein } \\
\text { mg.g }^{-1}\end{array}$ & $\begin{array}{c}\text { Carbohydrate } \\
\text { mg.g }^{-1}\end{array}$ & $\begin{array}{c}\text { Nitrogen } \\
\text { mg.kg-1 }\end{array}$ & $\begin{array}{c}\text { Phosphorus } \\
\text { mg.kg-1 }^{-1}\end{array}$ & $\begin{array}{c}\text { Potassium } \\
\text { mg.kg-1 }\end{array}$ & \begin{tabular}{|l|} 
Calcium \\
mg.kg-1 $^{-1}$
\end{tabular} & $\begin{array}{c}\text { Iron } \\
\text { mg.kg-1 }^{-1}\end{array}$ \\
\hline \multirow{6}{*}{ T. aestivum } & Control & 184.24 & 230.56 & 32041.55 & 2336.67 & 9047.43 & 7618.78 & 129.89 \\
\hline & B1 & 241.62 & 314.89 & 42021.59 & 2750.52 & 10555.82 & 8085.04 & 177.47 \\
\hline & B2 & 254.52 & 291.72 & 44264.17 & 2598.20 & 10210.15 & 8737.96 & 210.69 \\
\hline & B3 & 252.84 & 278.05 & 43972.50 & 2866.62 & 10153.99 & 7968.21 & 171.57 \\
\hline & B4 & 235.59 & 299.09 & 40972.13 & 2661.77 & 10469.07 & 8841.02 & 171.90 \\
\hline & B5 & 212.19 & 344.01 & 36902.48 & 3287.30 & 9837.22 & 8242.00 & 150.31 \\
\hline \multirow{6}{*}{ T. durum } & Control & 207.50 & 270.37 & 36086.53 & 2172.39 & 7762.40 & 7267.50 & 113.36 \\
\hline & B1 & 258.39 & 302.49 & 44937.34 & 2926.86 & 10408.07 & 8231.68 & 178.97 \\
\hline & B2 & 251.99 & 308.76 & 43824.00 & 2540.35 & 10117.96 & 7612.83 & 173.07 \\
\hline & B3 & 287.96 & 356.79 & 50079.67 & 3341.37 & 9518.49 & 8316.61 & 263.34 \\
\hline & B3 & 233.19 & 349.63 & 40555.52 & 2786.40 & 10231.02 & 7734.57 & 194.83 \\
\hline & B5 & 261.76 & 311.45 & 45523.18 & 4350.08 & 9943.96 & 7858.67 & 188.77 \\
\hline \multicolumn{2}{|c|}{ Tukey 0.01} & 3.57 & 0.926 & 621.566 & 15.931 & 199.582 & 165.029 & 5.327 \\
\hline
\end{tabular}

B1: Bradyrhizobium sp. (Vigna), B2: Rhizobium leguminosarum bv. viciae, B3: Bradyrhizobium Mungbean, B4: Mesorhizobium ciceri, B5: Rhizobium leguminosarum bv phaseoli

The results also revealed that NPK fertilizer had a significant effect on all nutrient contents of the leaves in both wheat species (see Table 13). In addition, using $360 \mathrm{~kg} . \mathrm{ha}^{-}$ ${ }^{1}$ of NPK for Triticum durum led to the highest values of nitrogen, phosphorus, and protein. Moreover, $120 \mathrm{~kg} \cdot \mathrm{ha}^{-1} \mathrm{NPK}$ of Triticum aestivum and $240 \mathrm{~kg} \cdot \mathrm{ha}^{-1} \mathrm{NPK}$ of Triticum aestivum led to the maximum values of potassium and calcium, respectively. Furthermore, adding $120 \mathrm{~kg} \cdot \mathrm{ha}^{-1}$ NPK of Triticum durum brought about the highest iron and carbohydrate content of the leaves.

Table 14 presents the data related to the effects of the chemical fertilizer combined with biofertilizer on the nutrient contents of the leaves. As observed, the highest values of nitrogen and protein contents of the leaves were obtained at $360 \mathrm{~kg} \cdot \mathrm{ha}^{-1}$ of NPK with B3. On the other hand the maximum value of phosphorus contents of the leaves was obtained at $360 \mathrm{~kg} \cdot \mathrm{ha}^{-1}$ of NPK with B5, while the greatest values of potassium and calcium were obtained in $240 \mathrm{~kg} \cdot \mathrm{ha}^{-1}$ of NPK with B4. Moreover, adding $120 \mathrm{~kg} \cdot \mathrm{ha}^{-1}$ with B3 led to the maximum values of iron and carbohydrate.

The interaction effects of different species of rhizobial bacteria and different levels of NPK on the two wheat species are presented in Table 15. Adding different types of rhizobial bacteria to the soil at different levels of NPK led to significant increase in Fe, $\mathrm{P}, \mathrm{N}, \mathrm{Ca}, \mathrm{K}$, protein, and the leaves' carbohydrate contents in both wheat species. Application of $360 \mathrm{~kg} \cdot \mathrm{ha}^{-1}$ of NPK with B3 led to the highest nitrogen and protein 
contents of the leaves in Triticum durum. The highest values of carbohydrate, phosphorus, and iron were recorded by utilizing $360 \mathrm{~kg} \cdot \mathrm{ha}^{-1}$ of NPK with B4 of Triticum durum, $120 \mathrm{~kg} \cdot \mathrm{ha}^{-1}$ of NPK with B5 of Triticum durum, and $\left(120 \mathrm{~kg} \cdot \mathrm{ha}^{-1}\right.$ of NPK with B3 of Triticum durum, respectively, while the highest values of potassium and calcium were obtained through $240 \mathrm{~kg}^{-h^{-1}}$ of NPK with B4 of Triticum aestivum.

Table 13. Interaction effect of wheat species and chemical fertilizer on some nutrient content of leaves

\begin{tabular}{|c|c|c|c|c|c|c|c|c|}
\hline $\begin{array}{l}\text { Wheat } \\
\text { species }\end{array}$ & $\begin{array}{l}\text { Chemical } \\
\text { fertilizer } \\
\left({\left.\mathrm{kg} . h a^{-1}\right)}^{-1}\right.\end{array}$ & $\begin{array}{l}\text { Protein } \\
\text { mg.g }\end{array}$ & $\begin{array}{c}\text { Carbohydrate } \\
\text { mg.g }\end{array}$ & $\begin{array}{l}\text { Nitrogen } \\
\text { mg.kg-1 }\end{array}$ & $\begin{array}{c}\text { Phosphorus } \\
\text { mg.kg }^{-1}\end{array}$ & $\begin{array}{c}\text { Potassium } \\
\text { mg.kg-1 }\end{array}$ & $\begin{array}{l}\text { Calcium } \\
\text { mg.kg-1 }\end{array}$ & $\begin{array}{c}\text { Iron } \\
\text { mg.kg-1 }\end{array}$ \\
\hline \multirow{3}{*}{ T. aestivum } & NPK1 & 217.05 & 29 & 37747.63 & 2355.21 & 10104.45 & 7965.86 & 148.11 \\
\hline & NPK2 & 222.61 & 317.32 & 38714.14 & 2858.63 & 10035.05 & 8495.70 & 161.28 \\
\hline & NPK3 & 250.85 & 266.25 & 43625.44 & 3036.70 & 9997.34 & 8284.95 & 196.53 \\
\hline \multirow{3}{*}{ T. durum } & NPK1 & 222.81 & 325.33 & 38749.83 & 3141.00 & 9833.16 & 7698.24 & 209.77 \\
\hline & NPK2 & 249.90 & 308.28 & 43461.63 & 2723.64 & 9550.48 & 7921.99 & 170.37 \\
\hline & NPK3 & 277.68 & 316.14 & 48291.65 & 3194.08 & 9607.31 & 7890.70 & 176.02 \\
\hline \multicolumn{2}{|c|}{ Tukey 0.01} & 2.24 & 0.58 & 389.437 & 9.981 & 125.046 & 103.398 & 3.338 \\
\hline
\end{tabular}

NPK1 $=120 \mathrm{~kg} \cdot \mathrm{ha}^{-1}, \mathrm{NPK} 2=240 \mathrm{~kg} \cdot \mathrm{ha}^{-1}, \mathrm{NPK} 3=360 \mathrm{~kg} \cdot \mathrm{ha}^{-1}$

Table 14. Interaction effect of chemical fertilizer and rhizobial bacteria on some nutrient content of leaves

\begin{tabular}{|c|c|c|c|c|c|c|c|c|}
\hline $\begin{array}{l}\text { Chemical } \\
\text { fertilizer } \\
\left(\text { kg.ha }^{-1}\right)\end{array}$ & $\begin{array}{c}\text { Bacteria } \\
\text { species }\end{array}$ & $\begin{array}{c}\text { Protein } \\
\text { mg.g }^{-1}\end{array}$ & $\underset{\mathrm{mg}^{-\mathrm{g}^{-1}}}{\text { Carbohydrate }}$ & $\begin{array}{c}\text { Nitrogen } \\
\text { mg.kg-1 }^{-1}\end{array}$ & $\begin{array}{c}\text { Phosphorus } \\
\text { mg.kg-1 }\end{array}$ & $\begin{array}{c}\text { Potassiu } \\
\text { m mg.kg-1 }\end{array}$ & $\begin{array}{l}\text { Calcium } \\
\text { mg.kg }^{-1}\end{array}$ & $\begin{array}{c}\text { Iron } \\
\text { mg.kg }^{-1}\end{array}$ \\
\hline \multirow{6}{*}{ NPK1 } & Control & 172.58 & 250.71 & 30014.22 & 1894.74 & 9064.47 & 7483.87 & 135.78 \\
\hline & B1 & 239.55 & 311.26 & 41661.58 & 2627.63 & 10505.41 & 7885.47 & 142.63 \\
\hline & B2 & 225.49 & 303.63 & 39215.14 & 2550.27 & 9899.13 & 7882.97 & 151.98 \\
\hline & B3 & 246.90 & 356.81 & 42938.43 & 2631.99 & 10036.23 & 7728.07 & 312.42 \\
\hline & B4 & 220.66 & 309.11 & 38375.89 & 2700.99 & 10668.13 & 8163.23 & 157.33 \\
\hline & B5 & 214.40 & 331.24 & 37287.13 & 4083.02 & 9639.46 & 7848.67 & 173.52 \\
\hline \multirow{6}{*}{ NPK2 } & Control & 204.37 & 266.29 & 35542.27 & 2371.15 & 7993.57 & 7479.29 & 110.24 \\
\hline & B1 & 236.24 & 344.77 & 41084.41 & 2955.75 & 10268.68 & 8135.42 & 166.92 \\
\hline & B2 & 234.00 & 308.11 & 40694.83 & 2512.56 & 10079.10 & 7900.04 & 176.02 \\
\hline & B3 & 259.33 & 308.44 & 45101.62 & 2725.65 & 10024.42 & 8606.24 & 181.87 \\
\hline & B4 & 241.08 & 315.80 & 41927.17 & 2926.44 & 10685.93 & 8838.98 & 191.96 \\
\hline & B5 & 242.52 & 333.39 & 42177.01 & 3255.26 & 9704.90 & 8293.08 & 167.92 \\
\hline \multirow{6}{*}{ NPK3 } & Control & 210.65 & & 36635.62 & & 8156.72 & 7366.26 & 118.84 \\
\hline & B1 & 274.23 & 270.04 & 47692.40 & 2932.69 & 10671.75 & 8454.18 & 225.10 \\
\hline & B2 & 300.28 & 288.97 & 52222.28 & 2644.99 & 10513.95 & 8743.18 & 247.64 \\
\hline & B3 & 304.97 & 287.01 & 53038.20 & 3954.35 & 9448.07 & 8092.92 & 158.08 \\
\hline & B4 & 241.43 & 348.17 & 41988.42 & 2544.82 & 9696.07 & 7861.17 & 200.81 \\
\hline & B5 & 254.00 & 318.56 & 44174.36 & 4117.79 & 10327.41 & 8009.25 & 167.17 \\
\hline \multicolumn{2}{|c|}{ Tukey 0.01} & 4.65 & 1.205 & 808.749 & 20.728 & 259.685 & 214.728 & 6.932 \\
\hline
\end{tabular}

B1: Bradyrhizobium sp. (Vigna), B2: Rhizobium leguminosarum bv. viciae, B3: Bradyrhizobium Mungbean, B4: Mesorhizobium ciceri, B5: Rhizobium leguminosarum bv phaseoli. NPK1 = $120 \mathrm{~kg} . \mathrm{ha}^{-1}$, NPK2 = $240 \mathrm{~kg} \cdot \mathrm{ha}^{-1}$, NPK3 = $360 \mathrm{~kg} \cdot \mathrm{ha}^{-1}$ 
Table 15. Interaction effect of wheat species, chemical fertilizer and rhizobial species on some nutrient content of leaves

\begin{tabular}{|c|c|c|c|c|c|c|c|c|c|}
\hline $\begin{array}{l}\text { Wheat } \\
\text { species }\end{array}$ & $\begin{array}{c}\text { Chemical } \\
\text { fertilizer } \\
\left(\mathrm{kg}^{-h^{-1}}\right)\end{array}$ & $\begin{array}{c}\text { Bacteria } \\
\text { species }\end{array}$ & $\begin{array}{l}\text { Protein } \\
\text { mg.g-1 }\end{array}$ & $\begin{array}{c}\text { Carbohydrate } \\
\text { mg.g }^{-1}\end{array}$ & $\begin{array}{l}\text { Nitrogen } \\
\text { mg.kg }^{-1}\end{array}$ & $\begin{array}{c}\text { Phosphorus } \\
\text { mg.kg-1 }\end{array}$ & $\begin{array}{c}\text { Potassium } \\
\text { mg.kg }^{-1}\end{array}$ & $\begin{array}{l}\text { Calcium } \\
\text { mg.kg }^{-1}\end{array}$ & $\begin{array}{c}\text { Iron } \\
\text { mg.kg-1 }\end{array}$ \\
\hline \multirow{18}{*}{ T. aestivum } & \multirow{6}{*}{ NPK1 } & Control & 177.96 & 233.90 & 30950.32 & 2070.93 & 9501.22 & 7836.17 & 137.28 \\
\hline & & B1 & 241.53 & 268.36 & 42005.92 & 2231.45 & 10734.78 & 7984.77 & 149.98 \\
\hline & & B2 & 236.95 & 314.09 & 41208.25 & 2552.93 & 10088.08 & 8063.87 & 137.28 \\
\hline & & B3 & 229.06 & 313.15 & 39837.23 & 2447.81 & 10054.35 & 7752.07 & 166.17 \\
\hline & & B4 & 230.87 & 289.54 & 40150.90 & 2073.90 & 10588.20 & 8103.87 & 147.98 \\
\hline & & B5 & 185.92 & 354.50 & 32333.16 & 2754.26 & 9660.07 & 8054.37 & 149.98 \\
\hline & \multirow{6}{*}{ NPK2 } & Control & 167.25 & 242.17 & 29087.13 & 2438.10 & 8924.14 & 7399.21 & 117.59 \\
\hline & & B1 & 229.05 & 406.81 & 39834.73 & 2669.14 & 9720.69 & 8215.98 & 166.17 \\
\hline & & B2 & 226.49 & 296.13 & 39389.73 & 2475.00 & 9931.38 & 8150.51 & 200.56 \\
\hline & & B3 & 241.49 & 293.03 & 41998.92 & 2645.24 & 10674.82 & 8093.69 & 182.37 \\
\hline & & B4 & 234.41 & 320.56 & 40766.58 & 3438.10 & 11240.79 & 10583.01 & 166.67 \\
\hline & & B5 & 236.94 & 345.23 & 41207.75 & 3486.21 & 9718.50 & 8531.78 & 134.28 \\
\hline & \multirow{6}{*}{ NPK3 } & Control & 207.50 & 215.62 & 36087.20 & 2501.00 & 8716.94 & 7620.97 & 134.78 \\
\hline & & B1 & 254.29 & 269.51 & 44224.11 & 3350.98 & 11212.00 & 8054.37 & 216.26 \\
\hline & & B2 & 300.12 & 264.93 & 52194.53 & 2766.67 & 10611.00 & 9999.50 & 294.23 \\
\hline & & B3 & 287.97 & 227.96 & 50081.34 & 3506.81 & 9732.80 & 8058.87 & 166.17 \\
\hline & & B4 & 241.49 & 287.17 & 41998.92 & 2473.31 & 9578.22 & 7836.17 & 201.06 \\
\hline & & B5 & 213.71 & 332.30 & 37166.54 & 3621.43 & 10133.08 & 8139.83 & 166.67 \\
\hline \multirow{18}{*}{ T. durum } & \multirow{6}{*}{ NPK1 } & Control & 167.20 & & 29078.13 & 1718.55 & 8627.71 & 7131.56 & 134.28 \\
\hline & & B1 & 237.57 & 354.16 & 41317.25 & 3023.81 & 10276.04 & 7786.17 & 135.28 \\
\hline & & B2 & 214.03 & 293.17 & 37222.04 & 2547.62 & 9710.19 & 7702.07 & 166.67 \\
\hline & & B3 & 264.73 & 400.46 & 46039.63 & 2816.17 & 10018.12 & 7704.07 & 458.67 \\
\hline & & B4 & 210.45 & 328.69 & 36600.87 & 3328.07 & 10748.05 & 8222.58 & 166.67 \\
\hline & & B5 & 242.89 & 307.99 & 42241.09 & 5411.79 & 9618.84 & 7642.97 & 197.06 \\
\hline & \multirow{6}{*}{ NPK2 } & Control & 241.49 & 290.42 & 41997.42 & 2304.21 & 7063.00 & 7559.37 & 102.90 \\
\hline & & B1 & 243.42 & 282.73 & 42334.09 & 3242.36 & 10816.67 & 8054.87 & 167.67 \\
\hline & & B2 & 241.50 & 320.08 & 41999.92 & 2550.12 & 10226.81 & 7649.57 & 151.48 \\
\hline & & B3 & 277.17 & 323.85 & 48204.32 & 2806.07 & 9374.03 & 9118.79 & 181.37 \\
\hline & & B4 & 247.75 & 311.04 & 43087.77 & 2414.79 & 10131.08 & 7094.96 & 217.26 \\
\hline & & B5 & 248.09 & 321.55 & 43146.27 & 3024.31 & 9691.30 & 8054.37 & 201.56 \\
\hline & \multirow{6}{*}{ NPK3 } & Control & 213.81 & 253.19 & 37184.04 & 2494.40 & 7596.50 & 7111.56 & 102.90 \\
\hline & & B1 & 294.17 & 270.58 & 51160.68 & 2514.40 & 10131.50 & 8853.98 & 233.95 \\
\hline & & B2 & 300.44 & 313.02 & 52250.03 & 2523.31 & 10416.89 & 7486.87 & 201.06 \\
\hline & & B3 & 321.97 & 346.06 & 55995.06 & 4401.88 & 9163.33 & 8126.98 & 149.98 \\
\hline & & B4 & 241.37 & 409.16 & 41977.92 & 2616.33 & 9813.92 & 7886.17 & 200.56 \\
\hline & & B5 & 294.30 & 304.81 & 51182.18 & 4614.14 & 10521.74 & 7878.67 & 167.67 \\
\hline \multicolumn{3}{|c|}{ кey 0.01} & 7.25 & 1.879 & 1260.856 & 32.316 & 404.854 & 334.765 & 10.807 \\
\hline
\end{tabular}

B1: Bradyrhizobium sp. (Vigna), B2: Rhizobium leguminosarum bv. viciae, B3: Bradyrhizobium Mungbean, B4: Mesorhizobium ciceri, B5: Rhizobium leguminosarum bv phaseoli. NPK1 $=120 \mathrm{~kg} \cdot \mathrm{ha}^{-1}$, NPK2 $=240 \mathrm{~kg} \cdot \mathrm{ha}^{-1}$, NPK3 $=360 \mathrm{~kg} \cdot \mathrm{ha}^{-1}$

\section{Yield components}

The results presented in Table 16 reveal that, compared with the control treatment, soil application of different rhizobial bacteria had a significant effect on some yield 
components. In addition, using B4 led to the maximum values of total dry weight of 54.31 g.plant ${ }^{-1}$, spike weight of $8.09 \mathrm{~g}$, grain number of 106.22 , and biological yield of $7895.18 \mathrm{~kg} . \mathrm{ha}^{-1}$, and utilizing B3 resulted in the highest grain yield of $2823.15 \mathrm{~kg} . \mathrm{ha}^{-1}$ and harvest index of $38.43 \%$.

Table 16. Effects of different species of rhizobial bacteria on some yield components

\begin{tabular}{c|c|c|c|c|c|c|c|c|c}
\hline $\begin{array}{c}\text { Bacterial } \\
\text { species }\end{array}$ & $\begin{array}{c}\text { Total dry } \\
\text { weight }_{\text {g.pot }^{-1}}\end{array}$ & $\begin{array}{c}\text { Spike } \\
\text { length } \\
\text { plant }^{-1}\end{array}$ & $\begin{array}{c}\text { Spike } \\
\text { weight. } \\
\text { plant }^{-1}\end{array}$ & $\begin{array}{c}\text { Spikelet } \\
\text { number } \\
\text { plant }^{-1}\end{array}$ & $\begin{array}{c}\text { Grain } \\
\text { number } \\
\text { plant }^{-1}\end{array}$ & $\begin{array}{c}\text { Grain } \\
\text { yield } \\
\text { kg.ha }^{-1}\end{array}$ & $\begin{array}{c}\text { Biological } \\
\text { yield } \\
\text { kg.ha }^{-1}\end{array}$ & $\begin{array}{c}\text { Weight of } \\
\text { 1000 grain (g) }\end{array}$ & $\begin{array}{c}\text { Harvest } \\
\text { index \% }\end{array}$ \\
\hline Control & 38.80 & 8.07 & 5.54 & 17.33 & 68.75 & 1819.77 & 5492.33 & 47.99 & 33.68 \\
B1 & 52.73 & 8.51 & 7.31 & 18.50 & 95.28 & 2550.29 & 7464.03 & 48.49 & 34.28 \\
B2 & 54.05 & 8.33 & 7.59 & 18.83 & 97.08 & 2708.82 & 7650.86 & 50.40 & 36.22 \\
B3 & 53.95 & 8.33 & 7.53 & 18.33 & 95.72 & 2823.15 & 7636.71 & 53.47 & 38.43 \\
B4 & 54.31 & 8.60 & 8.09 & 18.83 & 106.22 & 2780.06 & 7686.72 & 47.64 & 37.04 \\
B5 & 53.11 & 8.80 & 7.76 & 19.17 & 105.83 & 2661.63 & 7517.50 & 46.68 & 35.54 \\
\hline Tukey 0.05 & 3.31 & n.s. & 0.70 & n.s. & 6.578 & 271.42 & 468.25 & n.s. & 4.45 \\
\hline
\end{tabular}

B1: Bradyrhizobium sp. (Vigna), B2: Rhizobium leguminosarum bv. viciae, B3: Bradyrhizobium Mungbean, B4: Mesorhizobium ciceri, B5: Rhizobium leguminosarum bv phaseoli

According to the results presented in Table 17, it can clearly be observed that adding $360 \mathrm{~kg} \cdot \mathrm{ha}^{-1}$ resulted in the maximum increment of total dry weight, spike weight, grain number, grain yield, and biological yield. Moreover, using $120 \mathrm{~kg}^{-h^{-1}}$ of NPK led to the highest value of harvest index.

According to Table 18, some yield components were affected by wheat species, such that Triticum aestivum surpassed Triticum durum regarding spike length, grain number, and harvest index, while Triticum durum surpassed Triticum aestivum significantly in terms of total dry weight, spike weight, grain yield, biological yield, and weight of 1000 grains.

Table 17. Effects of different levels of chemical fertilizer on some yield components

\begin{tabular}{|c|c|c|c|c|c|c|c|c|c|}
\hline $\begin{array}{l}\text { Chemical } \\
\text { fertilizer } \\
\left(\mathrm{kg.ha}^{-1}\right)\end{array}$ & $\begin{array}{c}\text { Total dry } \\
\text { weight } \\
\text { g.pot }^{-1}\end{array}$ & $\begin{array}{l}\text { Spike } \\
\text { length } \\
\text { plant }^{-1}\end{array}$ & $\begin{array}{c}\text { Spike } \\
\text { weight } \\
\text { plant }^{-1}\end{array}$ & $\begin{array}{c}\text { Spikelet } \\
\text { number } \\
\text { plant }^{-1}\end{array}$ & $\begin{array}{c}\text { Grain } \\
\text { number } \\
\text { plant }^{-1}\end{array}$ & $\begin{array}{c}\text { Grain } \\
\text { yield } \\
\text { kg.ha-1 }\end{array}$ & \begin{tabular}{|c|} 
Biological \\
yield \\
kg.ha-1
\end{tabular} & $\begin{array}{c}\text { Weight } \\
\text { of } 1000 \\
\text { grain (g) }\end{array}$ & $\begin{array}{l}\text { Harvest } \\
\text { index \% }\end{array}$ \\
\hline NPK1 & 48.26 & 8.20 & 6.54 & 18.42 & 84.15 & 2452.47 & 6830.70 & 42.64 & 38.31 \\
\hline NPK2 & 49.44 & 8.33 & 7.16 & 18.42 & 93.76 & 2551.62 & 6998.19 & 42.41 & 37.12 \\
\hline NPK3 & 55.78 & 8.80 & 8.21 & 18.67 & 106.53 & 2632.70 & 7895.18 & 41.64 & 34.22 \\
\hline Tukey 0.05 & 1.91 & n.s. & 0.41 & n.s. & 3.80 & 156.86 & 270.6 & n.s. & 2.57 \\
\hline
\end{tabular}

NPK1 = $120 \mathrm{~kg} \cdot \mathrm{ha}^{-1}$, NPK2 = $240 \mathrm{~kg} \cdot \mathrm{ha}^{-1}, \mathrm{NPK} 3=360 \mathrm{~kg} \cdot \mathrm{ha}^{-1}$

Table 18. Effects of wheat species on some yield components

\begin{tabular}{c|c|c|c|c|c|c|c|c|c}
\hline $\begin{array}{c}\text { Wheat } \\
\text { species }\end{array}$ & $\begin{array}{c}\text { Total dry } \\
\text { weight } \\
\text { g.pot }^{-1}\end{array}$ & $\begin{array}{c}\text { Spike } \\
\text { length } \\
\text { plant }^{-1}\end{array}$ & $\begin{array}{c}\text { Spike } \\
\text { weight } \\
\text { plant }^{-1}\end{array}$ & $\begin{array}{c}\text { Spikelet } \\
\text { number } \\
\text { plant }^{-1}\end{array}$ & $\begin{array}{c}\text { Grain } \\
\text { number } \\
\text { plant }^{-1}\end{array}$ & $\begin{array}{c}\text { Grain } \\
\text { yield } \\
\text { kg/ha }\end{array}$ & $\begin{array}{c}\text { Biological } \\
\text { yield kg/ha }\end{array}$ & $\begin{array}{c}\text { Weight } \\
\text { of 1000 } \\
\text { grain }(\mathbf{g})\end{array}$ & $\begin{array}{c}\text { Harvest } \\
\text { index } \\
\text { \% }\end{array}$ \\
\hline T. aestivum & 45.19 & 9.72 & 6.47 & 18.50 & 105.94 & 2465.78 & 6396.43 & 42.03 & 38.91 \\
T. durum & 57.13 & 7.16 & 8.13 & 18.50 & 83.69 & 2648.79 & 8086.29 & 56.19 & 32.82 \\
\hline Tukey 0.05 & 1.299 & 0.67 & 0.28 & n.s. & 2.58 & 106.60 & 183.91 & 2.4 & 1.75 \\
\hline
\end{tabular}


The results presented in Table 19 revealed that different species of rhizobial bacteria had a significant effect on some yield components of both wheat species. Applying B2 with Triticum durum resulted in the highest values of grain yield $\left(2941.26 \mathrm{~kg} . \mathrm{ha}^{-1}\right)$, total dry weight of plant (63.04 g.plant $\left.{ }^{-1}\right)$, and biological yield (8922.86 kg.ha-1). Also, B4 with Triticum durum led to the highest value of spike weight $(9.21 \mathrm{~g})$. Moreover, the highest value of grain number (127.50) was obtained by utilizing B5 with Triticum aestivum, and the maximum value of harvest index (45.76\%) was obtained as a result of using B3 with Triticum aestivum.

Table 19. Interaction effect of wheat species and rhizobial bacteria on some yield components

\begin{tabular}{|c|c|c|c|c|c|c|c|c|c|c|}
\hline $\begin{array}{l}\text { Wheat } \\
\text { species }\end{array}$ & $\begin{array}{c}\text { Bacterial } \\
\text { species }\end{array}$ & $\begin{array}{c}\text { Total dry } \\
\text { weight } \\
\text { g.pot }{ }^{-1}\end{array}$ & \begin{tabular}{|c|}
$\begin{array}{l}\text { Spike } \\
\text { length } \\
\text { plant }^{-1}\end{array}$ \\
\end{tabular} & $\begin{array}{l}\text { Spike } \\
\text { weight } \\
\text { plant }^{-1}\end{array}$ & $\begin{array}{c}\text { Spikelet } \\
\text { number } \\
\text { plant }^{-1}\end{array}$ & $\begin{array}{c}\text { Grain } \\
\text { number } \\
\text { plant }^{-1}\end{array}$ & $\begin{array}{c}\text { Grain } \\
\text { yield } \\
\text { kg.ha-1 }\end{array}$ & $\begin{array}{c}\text { Biological } \\
\text { yield } \\
\text { kg.ha }^{-1}\end{array}$ & $\begin{array}{c}\text { Weight } \\
\text { of } 1000 \\
\text { grain (g) }\end{array}$ & $\begin{array}{l}\text { Harvest } \\
\text { index } \%\end{array}$ \\
\hline \multirow{6}{*}{ T. aestivum } & Control & 33.02 & 8.93 & 4.77 & 17.33 & 75.00 & 1631.83 & 4673.43 & 39.12 & 35.11 \\
\hline & B1 & 47.39 & 9.67 & 6.36 & 18.33 & 105.50 & 2342.69 & 6707.24 & 39.56 & 35.01 \\
\hline & B2 & 45.07 & 9.27 & 6.54 & 18.67 & 104.83 & 2476.37 & 6378.86 & 42.63 & 39.35 \\
\hline & B3 & 46.61 & 9.50 & 6.77 & 18.00 & 109.17 & 2939.37 & 6597.78 & 48.63 & 45.76 \\
\hline & B4 & 48.05 & 10.57 & 6.97 & 19.33 & 113.67 & 2663.52 & 6800.66 & 43.36 & 40.21 \\
\hline & B5 & 51.01 & 10.40 & 7.42 & 19.33 & 127.50 & 2740.90 & 7220.57 & 38.88 & 38.02 \\
\hline \multirow{6}{*}{ T. durum } & Control & & 7.21 & 6.31 & 17.33 & 62.50 & 2007.71 & & 56.87 & 32.26 \\
\hline & B1 & 58.08 & 7.34 & 8.27 & 18.67 & 85.06 & 2757.88 & 8220.81 & 57.42 & 33.55 \\
\hline & B2 & 63.04 & 7.40 & 8.64 & 19.00 & 89.33 & 2941.26 & 8922.86 & 58.17 & 33.09 \\
\hline & B3 & 61.29 & 7.17 & 8.29 & 18.67 & 82.28 & 2706.93 & 8675.63 & 58.30 & 31.09 \\
\hline & B4 & 60.57 & 6.63 & 9.21 & 18.33 & 98.78 & 2896.60 & 8572.78 & 51.92 & 33.86 \\
\hline & B5 & 55.21 & 7.20 & 8.09 & 19.00 & 84.17 & 2582.37 & 7814.42 & 54.47 & 33.07 \\
\hline \multicolumn{2}{|c|}{ Tukey 0.05} & 5.409 & n.s. & 1.15 & n.s. & 10.76 & 443.82 & 765.67 & n.s. & 7.28 \\
\hline
\end{tabular}

B1: Bradyrhizobium sp. (Vigna), B2: Rhizobium leguminosarum bv. viciae, B3: Bradyrhizobium Mungbean, B4: Mesorhizobium ciceri, B5: Rhizobium leguminosarum bv phaseoli

In addition, the two wheat species were significantly different in terms NPK levels (see Table 20). In general, the highest values of most yield components were observed at NPK3 for both species, while the highest values of weight of 1000 grains and harvest index were obtained by adding $240 \mathrm{~kg} \cdot \mathrm{ha}^{-1}$ of NPK of Triticum durum and $120 \mathrm{~kg} \cdot \mathrm{ha}^{-1}$ of NPK Triticum aestivum, respectively.

Table 20. Interaction effect of wheat species and chemical fertilizer on some yield components

\begin{tabular}{|c|c|c|c|c|c|c|c|c|c|c|}
\hline $\begin{array}{l}\text { Wheat } \\
\text { species }\end{array}$ & $\begin{array}{c}\text { Chemical } \\
\text { fertilizer } \\
\text { kg.ha-1 }^{-1}\end{array}$ & $\begin{array}{c}\text { Total dry } \\
\text { weight } \\
\text { g.pot }^{-1}\end{array}$ & \begin{tabular}{|c|} 
Spike \\
length \\
plant $^{-1}$ \\
\end{tabular} & $\begin{array}{l}\text { Spike } \\
\text { weight } \\
\text { plant }^{-1}\end{array}$ & $\begin{array}{c}\text { Spikelet } \\
\text { number } \\
\text { plant }^{-1}\end{array}$ & $\begin{array}{c}\text { Grain } \\
\text { number } \\
\text { plant }^{-1}\end{array}$ & $\begin{array}{c}\text { Grain } \\
\text { yield } \\
\text { kg.ha }\end{array}$ & $\begin{array}{c}\text { Biological } \\
\text { yield } \\
\text { kg.ha-1 }^{-1}\end{array}$ & $\begin{array}{c}\text { Weight } \\
\text { of } 1000 \\
\text { grain (g) }\end{array}$ & $\begin{array}{l}\text { Harvest } \\
\text { index \% }\end{array}$ \\
\hline \multirow{3}{*}{ T. aestivum } & & & 35 & 5.57 & 17.50 & 90.25 & 2346.15 & 5573.48 & 5.50 & +1.03 \\
\hline & NPK2 & 9 & 63 & 6.18 & 18.67 & 104.25 & 2503.26 & 6283.56 & 42.97 & 40.08 \\
\hline & NPK3 & 51.80 & 10.18 & 7.67 & 19.33 & 123.33 & 2547.93 & 7332.23 & 37.62 & 34.82 \\
\hline \multirow{3}{*}{ T. durum } & NPK1 & 14 & 7.04 & 7.50 & 19.33 & 78.06 & 2474.48 & .91 & 56.28 & 30.89 \\
\hline & NPK2 & 54.49 & 7.02 & 8.14 & 18.17 & 83.28 & 2648.27 & 7712.83 & 56.47 & 34.21 \\
\hline & NPK3 & 59.76 & 7.42 & 8.76 & 18.00 & 89.72 & 2823.62 & 8458.13 & 45.65 & 33.62 \\
\hline \multicolumn{2}{|c|}{ Tukey 0.05} & 3.31 & s & 0.70 & $\mathrm{n}$ & 6.58 & 271.42 & 468.25 & 6.19 & 4.45 \\
\hline
\end{tabular}

$\mathrm{NPK} 1=120 \mathrm{~kg} \cdot \mathrm{ha}^{-1}, \mathrm{NPK} 2=240 \mathrm{~kg} \cdot \mathrm{ha}^{-1}, \mathrm{NPK} 3=360 \mathrm{~kg} \cdot \mathrm{ha}^{-1}$ 
The results presented in Table 21 indicate the interaction effects of chemical fertilizer and rhizobial bacteria on some yield components. As observed, the highest values of total dry weight, spike weight, grain number, and biological yield were gained by adding $360 \mathrm{~kg} \cdot \mathrm{ha}^{-1}$ of NPK with B4, and the highest values of grain yield and harvest index were obtained by adding $240 \mathrm{~kg} \cdot \mathrm{ha}^{-1}$ of NPK with B4.

Table 21. Interaction effect of chemical fertilizer and rhizobial bacteria on some yield components

\begin{tabular}{|c|c|c|c|c|c|c|c|c|c|c|}
\hline $\begin{array}{c}\text { Chemical } \\
\text { fertilizer } \\
\text { kg.ha }^{-1}\end{array}$ & $\begin{array}{c}\text { Bacterial } \\
\text { species }\end{array}$ & $\begin{array}{c}\text { Total dry } \\
\text { weight } \\
\text { g.pot }^{-1}\end{array}$ & $\begin{array}{l}\text { Spike } \\
\text { length } \\
\text { plant }^{-1}\end{array}$ & $\begin{array}{l}\text { Spike } \\
\text { weight } \\
\text { plant }^{-1} \\
\end{array}$ & $\begin{array}{c}\text { Spikelet } \\
\text { number } \\
\text { plant }^{-1}\end{array}$ & $\begin{array}{c}\text { Grain } \\
\text { number } \\
\text { plant }^{-1}\end{array}$ & \begin{tabular}{|c|} 
Grain \\
yield \\
kg.ha $^{-1}$ \\
\end{tabular} & $\begin{array}{c}\text { Biological } \\
\text { yield } \\
\text { kg.ha-1 }^{-1} \\
\end{array}$ & $\begin{array}{c}\text { Weight } \\
\text { of } 1000 \\
\text { grain }(\mathrm{g})\end{array}$ & $\begin{array}{l}\text { Harvest } \\
\text { index \% }\end{array}$ \\
\hline \multirow{6}{*}{ NPK1 } & Control & 31.36 & 7.97 & 4.68 & 17.50 & 64.00 & 1622.55 & 4439.26 & 47.55 & 36.54 \\
\hline & B1 & 50.36 & 8.37 & 6.80 & 18.00 & 88.42 & 2379.34 & 7127.62 & 47.34 & 33.78 \\
\hline & B2 & 55.73 & 8.25 & 7.02 & 19.00 & 90.42 & 2836.99 & 7888.65 & 55.11 & 38.06 \\
\hline & B3 & 50.95 & 8.10 & 6.59 & 18.50 & 86.92 & 2751.12 & 7211.61 & 56.83 & 39.79 \\
\hline & B4 & 49.64 & 7.80 & 6.88 & 18.50 & 84.92 & 2384.05 & 7026.19 & 49.81 & 35.51 \\
\hline & B5 & 51.51 & 8.70 & 7.24 & 19.00 & 90.25 & 2487.85 & 7290.87 & 48.70 & 34.47 \\
\hline \multirow{6}{*}{ NPK2 } & Control & 43.07 & 8.25 & 6.31 & 18.00 & 78.00 & 1943.38 & 6096.25 & 45.01 & 31.90 \\
\hline & B1 & 54.18 & 8.25 & 7.21 & 18.00 & 99.50 & 2533.62 & 7669.26 & 47.47 & 33.05 \\
\hline & B2 & 50.68 & 8.00 & 7.25 & 18.00 & 93.58 & 2564.76 & 7173.39 & 49.80 & 36.06 \\
\hline & B3 & 48.18 & 8.10 & 6.96 & 18.00 & 87.50 & 2751.59 & 6819.53 & 55.53 & 41.99 \\
\hline & B4 & 50.44 & 8.75 & 7.780 & 19.00 & 103.00 & 3000.24 & 7139.42 & 51.39 & 42.37 \\
\hline & B5 & 50.10 & 8.60 & 7.44 & 19.50 & 101.00 & 2661.01 & 7091.30 & 49.14 & 37.48 \\
\hline \multirow{6}{*}{ NPK3 } & Control & 41.98 & 8.00 & 5.63 & 16.50 & 64.25 & 1893.37 & 5941.50 & 51.42 & 32.61 \\
\hline & B1 & 53.66 & 8.90 & 7.93 & 19.50 & 97.92 & 2737.91 & 7595.19 & 50.66 & 36.02 \\
\hline & B2 & 55.75 & 8.75 & 8.50 & 19.50 & 107.25 & 2724.70 & 7890.54 & 46.28 & 34.54 \\
\hline & B3 & 62.73 & 8.80 & 9.05 & 18.50 & 112.75 & 2966.74 & 8878.98 & 48.04 & 33.49 \\
\hline & B4 & 62.84 & 9.25 & 9.58 & 19.00 & 130.75 & 2955.89 & 8894.55 & 41.73 & 33.23 \\
\hline & B5 & 57.72 & 9.10 & 8.59 & 19.00 & 126.25 & 2836.05 & 8170.32 & 42.19 & 34.68 \\
\hline \multicolumn{2}{|c|}{ Tukey 0.05} & 7.11 & n.s. & 1.51 & n.s. & 14.13 & 583.11 & 1005.98 & n.s. & 9.56 \\
\hline
\end{tabular}

B1: Bradyrhizobium sp. (Vigna), B2: Rhizobium leguminosarum bv. viciae, B3: Bradyrhizobium Mungbean, B4: Mesorhizobium ciceri, B5: Rhizobium leguminosarum bv phaseoli. NPK1 $=120 \mathrm{~kg} \cdot \mathrm{ha}^{-1}$, NPK2 $=240 \mathrm{~kg} \cdot \mathrm{ha}^{-1}$, $\mathrm{NPK} 3=360 \mathrm{~kg} \cdot \mathrm{ha}^{-1}$

The results presented in Table 22 indicate that combining different species of rhizobium with different levels of NPK had significant effects on some yield components including total dry weight of plant, weight of spike, number of grains, grain yield, biological yield, and harvest index in both species. As observed, the highest grain number was obtained in Triticum aestivum with $360 \mathrm{~kg}^{-h a^{-1}}$ of NPK with B5, while the maximum total dry weight and biological yield were observed in Triticum durum with $120 \mathrm{~kg} \cdot \mathrm{ha}^{-1}$ of NPK with B2. Moreover, the greatest grain yield was achieved in Triticum aestivum by adding $120 \mathrm{~kg} \cdot \mathrm{ha}^{-1}$ of NPK with B3, and the highest value of spike weight was recorded in Triticum durum by adding $240 \mathrm{~kg} \cdot \mathrm{ha}^{-1}$ of NPK with B4. Furthermore, the highest value of harvest index was obtained in Triticum aestivum by adding $120 \mathrm{~kg} \cdot \mathrm{ha}^{-1}$ of NPK with B3. Figure 1 indicates that soil application of $120 \mathrm{~kg} \cdot \mathrm{ha}^{-1}$ of NPK with B2 increased the grain yield by $111.19 \%$ compared to the control. The results also showed that combining the lower level of NPK fertilizer with rhizobial inoculation had the greatest effect on the yield components. 
Table 22. Interaction effect of wheat species, chemical fertilizer and rhizobial bacteria on some yield components

\begin{tabular}{|c|c|c|c|c|c|c|c|c|c|c|c|}
\hline $\begin{array}{l}\text { Wheat } \\
\text { species }\end{array}$ & $\begin{array}{c}\text { Chemical } \\
\text { fertilizer } \\
\left(\text { kg.ha }^{-1}\right)\end{array}$ & $\begin{array}{c}\text { Bacterial } \\
\text { species }\end{array}$ & $\begin{array}{c}\text { Total dry } \\
\text { weight } \\
\text { g.pot }^{-1} \\
\end{array}$ & \begin{tabular}{|c|} 
Spike \\
length. \\
plant $^{-1}$
\end{tabular} & $\begin{array}{c}\text { Spike } \\
\text { weight. } \\
\text { plant }^{-1}\end{array}$ & \begin{tabular}{|c|}
$\begin{array}{c}\text { Spikelet } \\
\text { number } \\
\text { plant }^{-1}\end{array}$ \\
\end{tabular} & $\begin{array}{c}\text { Grain } \\
\text { number } \\
\text { plant }^{-1}\end{array}$ & $\begin{array}{c}\text { Grain } \\
\text { yield } \\
\text { kg.hat }^{-1}\end{array}$ & $\begin{array}{c}\text { Biological } \\
\text { yield } \\
\text { kg.ha }^{-1} \\
\end{array}$ & \begin{tabular}{|c|}
$\begin{array}{c}\text { Weight } \\
\text { of 1000 } \\
\text { grain (g) }\end{array}$ \\
\end{tabular} & $\begin{array}{l}\text { Harvest } \\
\text { index \% }\end{array}$ \\
\hline \multirow{18}{*}{ T. aestivum } & \multirow{6}{*}{ NPK1 } & Control & 31.60 & 8.80 & 5.12 & 16.00 & 81.00 & 1702.29 & 4472.75 & 37.12 & 38.06 \\
\hline & & B1 & 40.22 & 9.00 & 5.13 & 17.00 & 85.00 & 2036.33 & 5692.85 & 42.31 & 35.77 \\
\hline & & B2 & 38.16 & 9.50 & 5.27 & 19.00 & 84.00 & 2415.66 & 5401.27 & 50.79 & 44.72 \\
\hline & & B3 & 44.68 & 9.00 & 6.43 & 17.00 & 111.00 & 3362.11 & 6324.13 & 53.50 & 53.16 \\
\hline & & B4 & 38.80 & 9.60 & 5.72 & 18.00 & 90.00 & 2346.78 & 5491.86 & 46.06 & 42.73 \\
\hline & & B5 & 42.80 & 10.20 & 5.75 & 18.00 & 90.50 & 2213.73 & 6058.03 & 43.20 & 36.54 \\
\hline & \multirow{6}{*}{ NPK2 } & Control & 37.76 & 9.00 & 5.27 & 18.00 & 86.00 & 1715.50 & 5344.66 & 35.23 & 32.10 \\
\hline & & B1 & 52.88 & 10.00 & 6.96 & 18.00 & 122.00 & 2516.63 & 7484.78 & 36.43 & 33.62 \\
\hline & & B2 & 44.88 & 9.00 & 6.37 & 18.00 & 107.50 & 2460.01 & 6352.44 & 40.42 & 38.73 \\
\hline & & B3 & 37.96 & 9.20 & 5.48 & 18.00 & 86.50 & 2673.27 & 5372.97 & 54.59 & 49.75 \\
\hline & & B4 & 42.22 & 10.60 & 5.55 & 20.00 & 92.50 & 2659.12 & 5975.94 & 50.78 & 44.50 \\
\hline & & B5 & 50.66 & 10.00 & 7.48 & 20.00 & 131.00 & 2995.05 & 7170.56 & 40.38 & 41.77 \\
\hline & \multirow{6}{*}{ NPK3 } & Control & 29.69 & 9.00 & 3.93 & 18.00 & 58.00 & 1477.71 & 4202.88 & 45.00 & 35.16 \\
\hline & & B1 & 49.06 & 10.00 & 6.98 & 20.00 & 109.50 & 2475.11 & 6944.09 & 39.92 & 35.64 \\
\hline & & B2 & 52.16 & 9.30 & 7.99 & 19.00 & 123.00 & 2553.43 & 7382.87 & 36.67 & 34.59 \\
\hline & & B3 & 57.20 & 10.30 & 8.41 & 19.00 & 130.00 & 2782.73 & 8096.25 & 37.81 & 34.37 \\
\hline & & B4 & 63.12 & 11.50 & 9.65 & 20.00 & 158.50 & 2984.67 & 8934.18 & 33.26 & 33.41 \\
\hline & & B5 & 59.58 & 11.00 & 9.05 & 20.00 & 161.00 & 3013.92 & 8433.12 & 33.06 & 35.74 \\
\hline \multirow{18}{*}{ T. durum } & \multirow{6}{*}{ NPK1 } & Control & 31.13 & 7.13 & 4.25 & 19.00 & 47.00 & 1542.82 & 4405.76 & 57.98 & 35.02 \\
\hline & & B1 & 60.49 & 7.73 & 8.48 & 19.00 & 91.83 & 2722.34 & 8562.40 & 52.36 & 31.79 \\
\hline & & B2 & 73.31 & 7.00 & 8.76 & 19.00 & 96.83 & 3258.32 & 10376.03 & 59.432 & 31.40 \\
\hline & & B3 & 57.22 & 7.20 & 6.75 & 20.00 & 62.83 & 2140.13 & 8099.08 & 60.16 & 26.42 \\
\hline & & B4 & 60.48 & 6.00 & 8.05 & 19.00 & 79.83 & 2421.33 & 8560.51 & 53.57 & 28.28 \\
\hline & & B5 & 60.22 & 7.20 & 8.73 & 20.00 & 90.00 & 2761.97 & 8523.71 & 54.20 & 32.40 \\
\hline & \multirow{6}{*}{ NPK2 } & Control & 48.38 & 7.50 & 7.36 & 18.00 & 70.00 & 2171.27 & 6847.84 & 54.79 & 31.71 \\
\hline & & B1 & 55.49 & 6.50 & 7.45 & 18.00 & 77.00 & 2550.60 & 7853.74 & 58.51 & 32.48 \\
\hline & & B2 & 56.48 & 7.00 & 8.14 & 18.00 & 79.67 & 2669.50 & 7994.34 & 59.18 & 33.40 \\
\hline & & B3 & 58.40 & 7.00 & 8.45 & 18.00 & 88.50 & 2829.91 & 8266.10 & 56.48 & 34.24 \\
\hline & & B4 & 58.66 & 6.90 & 10.05 & 18.00 & 113.50 & 3341.35 & 8302.90 & 52.00 & 40.24 \\
\hline & & B5 & 49.54 & 7.20 & 7.40 & 19.00 & 71.00 & 2326.96 & 7012.03 & 57.89 & 33.19 \\
\hline & \multirow{6}{*}{ NPK3 } & Control & 54.26 & 7.00 & 7.32 & 15.00 & 70.50 & 2309.04 & 7680.11 & 57.85 & 30.065 \\
\hline & & B1 & 58.26 & 7.80 & 8.88 & 19.00 & 86.33 & 3000.71 & 8246.28 & 61.39 & 36.39 \\
\hline & & B2 & 59.33 & 8.20 & 9.02 & 20.00 & 91.50 & 2895.97 & 8398.21 & 55.90 & 34.48 \\
\hline & & B3 & 68.26 & 7.30 & 9.69 & 18.00 & 95.50 & 3150.74 & 9661.71 & 58.27 & 32.61 \\
\hline & & B4 & 62.56 & 7.00 & 9.52 & 18.00 & 103.00 & 2927.11 & 8854.92 & 50.19 & 33.06 \\
\hline & & B5 & 55.87 & 7.20 & 8.14 & 18.00 & 91.50 & 2658.17 & 7907.53 & 51.31 & 33.62 \\
\hline \multicolumn{3}{|c|}{ Tukey 0.05} & 11.12 & n.s & 2.37 & n.s. & 22.11 & 912.23 & 1573.76 & n.s. & 14.95 \\
\hline
\end{tabular}

B1: Bradyrhizobium sp. (Vigna), B2: Rhizobium leguminosarum bv. viciae, B3: Bradyrhizobium Mungbean, B4: Mesorhizobium ciceri, B5: Rhizobium leguminosarum bv phaseoli. NPK1 $=120 \mathrm{~kg} \cdot \mathrm{ha}^{-1}, \mathrm{NPK} 2=240 \mathrm{~kg} \cdot \mathrm{ha}^{-1}, \mathrm{NPK} 3=360 \mathrm{~kg} \cdot \mathrm{ha}^{-1}$

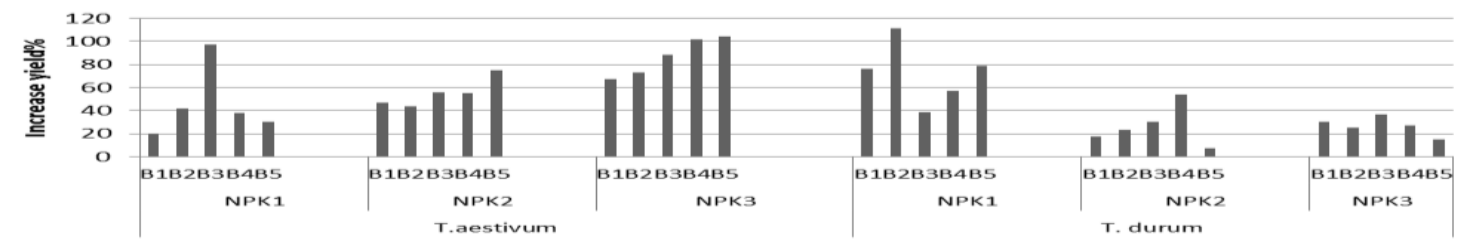

Figure 1. Interaction effect of wheat species, chemical fertilizer, and rhizobial species on percentage increase of yield 


\section{Discussion}

A common anthropogenic alteration to terrestrial systems is application of fertilizers. An increase in nutrient input can have a direct impact on soil microbial diversity or function by altering soil environments, or an indirect effect through plant-microbe feedbacks with potentially important effects on ecologically-important plant-associated mutualists (Simonsen et al., 2015). Chemical fertilizers can be used in order to increase soil nutrients and crop yields (Jia et al., 2018). Nitrogen (N), phosphorus (P), and potassium $(\mathrm{K})$ are the major nutrients required by the crop, and the reproductive capability, growth, and yield of the plant can negatively be affected by inadequate supply of any of these nutrients during crop growth (Okechukwu, 2011). However, excessive use of mineral fertilizers can generate several environmental problems such as potential pollution to soil, water, and air (Stajković-Srbinović et al., 2014). The present study was aimed at minimizing the use of chemical fertilizer and improving wheat production and environmental risks. The results showed that combining chemical fertilizer and biofertilizer can improve wheat growth and development. The positive effects of the biofertilizer on physiological parameters, biochemical contents of leaves, and yield components under study can be attributed to the fact that rhizobial bacteria are involved in the production of phytohormone, leading to changes in root morphology and physiology that resulted in an increase in nutrient and water uptake of the wheat species from the soil (Mia and Shamsuddin, 2010). Adesemoye and Kloepper (2009) pointed out that plant-PGPR interactions can lead to various benefits such as improvement in seed shoot weights, germination rate, yield, chlorophyll content, leaf area, hydraulic activity, and protein content. Given the production of siderophores and nutrient uptake due to better root system, rhizobial bacteria have mostly been used to promote photosynthetic pigments. Research has indicated that bacterial production of siderophores enhances chlorophyll content and growth of plants due to the selective iron uptake from the solutions of trace elements, and production of siderophores inhibits free radical formation, substantiates the oxidative stress, and prevents the uptake of heavy metals (Ullah et al., 2017). Moreover, the role of Rhizobium sp. in enhancement of stress tolerance leads to an increase in cell membrane stability (Mia and Shamsuddin, 2010) because cell membranes are one of the first targets of many plant stresses (Bajji et al., 2002). Due to urgent need for increased global wheat production, wheat tolerance to biotic and abiotic stresses should be should be improved more (ElBasyoni et al., 2017). As pointed out by Mehboob et al. (2011), growth and yield of wheat can be promoted by isolates of Rhizobium spp. Rhizobium inoculation can lead to yield enhancement in wheat parameters, which can be attributed to the fact that applying biofertilizers have been proved to lead to high quality yield and avoid environmental pollution (Das et al., 2008). The findings of the present study are in agreement with those of the studies carried out by Agamy et al. (2012) and Adnan et al. (2016). It should be noted that plant species and their genotypes are genetically different in terms of their ability to uptake and metabolize elements.

\section{Conclusion}

Based on the results of the present study, it was observed that the combination between lower levels of NPK fertilizer and rhizobial inoculation had the greatest effect on yield components; therefore, such combinations are recommended to be utilized. Recently, biofertilizers have become an important means in agriculture because they use 
beneficial rhizobial bacteria to improve wheat production in a more economical and environmentally friendly way. Therefore, we suggested that the influence of combined effect of NPK fertilizer and rhizobial inoculation on growth and yield of wheat in soil needs further investigation to arrive at a conclusion where the effects are synergistic.

Acknowledgements. The authors of the present study would like to thank the staff of the greenhouse for their support and help with this research. Sincere thanks also go to the reviewers and editors for their exceptionally helpful comments on the manuscript.

\section{REFERENCES}

[1] Abou-Taleb, S. M., Gomaa, E. F. (2012): Morphological and anatomical study on some wheat cultivars and their response to seasonal variations. - Australian Journal of Basic and Applied Sciences 6: 13-22.

[2] Adesemoye, A. O., Kloepper, J. W. (2009): Plant-microbes interactions in enhanced fertilizer-use efficiency. - Applied Microbiology and Biotechnology 85: 1-12.

[3] Adnan, M., Shah, Z., Khan, A., Khan, G. A., Ali, A., Khan, N. A., Saleem, N., Nawaz, S., Akbar, S., Samreen, S. (2014): Integrated effects of Rhizobial inoculum and inorganic fertilizers on wheat yield and yield components. - American Journal of Plant Sciences 5: 2066.

[4] Agamy, R., Mohamed, G., Rady, M. (2012): Influence of the application of fertilizer type on growth, yield, anatomical structure and some chemical components of wheat (Triticum aestivum L.) grown in newly reclaimed soil. - Australian Journal of Basic and Applied Sciences 6: 561-570.

[5] Al-Shamma, U. H., Al-Shahwany, A. W. (2014): Effect of mineral and bio-fertilizer application on growth and yield of wheat Triticum aestivum L. - Iraqi Journal of Science 55: 1484-1495.

[6] Bajji, M., Kinet, J.-M., Lutts, S. (2002): The use of the electrolyte leakage method for assessing cell membrane stability as a water stress tolerance test in durum wheat. - Plant Growth Regulation 36: 61-70.

[7] Biswas, J., Ladha, J., Dazzo, F. (2000): Rhizobia inoculation improves nutrient uptake and growth of lowland rice. - Soil Science Society of America Journal. DOI: $10.2136 /$ sssaj2000.6451644x.

[8] Dalaly, B., Al-Hakim, S. (1987): Food Analysis. - Mosel University, Iraq.

[9] Das, K., Dang, R., Shivananda, T. (2008): Influence of bio-fertilizers on the availability of nutrients $(\mathrm{N}, \mathrm{P}$ and $\mathrm{K})$ in soil in relation to growth and yield of Stevia rebaudiana grown in South India. - International Journal of Applied Research in Natural Products 1: 20-24.

[10] ElBasyoni, I., Saadalla, M., Baenziger, S., Bockelman, H., Morsy, S. (2017): Cell membrane stability and association mapping for drought and heat tolerance in a worldwide wheat collection. - Sustainability 9: 1606.

[11] Elghair, S. A. A. (2012): Effect of nitrogen on rhizobacteria associated with wheat shoot productivity. - Thesis Submitted to the Faculty of the Graduate College of the Oklahoma State University in partial fulfillment of the requirements for the Degree of Master of Science.

[12] Elia, Y., Al-Sahaf, N., Al-Khesraji, T. (1987): Preliminary studies on Orobanche aegyptiaca Pers. in tomato. - Iraqi J. Agric. Sci.'Zanco' 5: 233-244.

[13] Etesami, H., Alikhani, H. A., Jadidi, M., Aliakbari, A. (2009): Effect of superior IAA producing rhizobia on $\mathrm{N}, \mathrm{P}, \mathrm{K}$ uptake by wheat grown under greenhouse condition. World Appl. Sci. J 6: 1629-1633. 
[14] Fatima, Z., Zia, M., Chaudhary, M. F. (2006): Effect of Rhizobium strains and phosphorus on growth of soybean Glycine max and survival of Rhizobium and $\mathrm{P}$ solubilizing bacteria. - Pakistan Journal of Botany 38: 459.

[15] Gray, E., Smith, D. (2005): Intracellular and extracellular PGPR: commonalities and distinctions in the plant-bacterium signaling processes. - Soil Biology and Biochemistry 37: 395-412.

[16] Jia, Q., Kamran, M., Ali, S., Sun, L., Zhang, P., Ren, X., Jia, Z. (2018): Deficit irrigation and fertilization strategies to improve soil quality and alfalfa yield in arid and semi-arid areas of northern China. - Peer J 6: e4410.

[17] Lichtenthaler, H. K. (1987): Chlorophylls and carotenoids: pigments of photosynthetic biomembranes. - Methods in Enzymology 148: 350-382.

[18] Mehboob, I., Zahir, Z. A., Arshad, M., Tanveer, A., Azam, F. (2011): Growth promoting activities of different Rhizobium spp. in wheat. - Pak. J. Bot 43: 1643-1650.

[19] Mia, M. B., Shamsuddin, Z. (2010): Rhizobium as a crop enhancer and biofertilizer for increased cereal production. - African journal of Biotechnology 9: 6001-6009.

[20] Mitkees, R., Saad, H., Iman, M., Amer, H., Mahamoud, S. K. (1996): Importance of N2 fixing biofertilizer for decreasing the use of mineral nitrogen fertilizer for wheat plant. Egypt J. Appl. Sci 11: 34-41.

[21] Okechukwu, V. (2011): Effects of NPK fertilizer on growth, drymatter production and yield of eggplant in southwestern Nigeria. - Agric. Biol. J. N. Am. 2(7): 1117-1125.

[22] Premachandra, G., Saneoka, H., Kanaya, M., Ogata, S. (1991): Cell membrane stability and leaf surface wax content as affected by increasing water deficits in maize. - Journal of Experimental Botany 42: 167-171.

[23] Ryan, J., Estefon, G., Rashid, A. (2001): Soil and Plant Analysis Laboratory Manual, 2nd edn. National Agriculture Research Center (NARC) Islamabad, Pakistan. - Bull. Fac. Sci 31: 395-303.

[24] Sadasivam, S. (1996): Biochemical Methods. - New Age International, Delhi.

[25] Sessitsch, A., Howieson, J., Perret, X., Antoun, H., Martinez-Romero, E. (2002): Advances in Rhizobium research. - Critical Reviews in Plant Sciences 21: 323-378.

[26] Simonsen, A. K., Han, S., Rekret, P., Rentschler, C. S., Heath, K. D., Stinchcombe, J. R. (2015): Short-term fertilizer application alters phenotypic traits of symbiotic nitrogen fixing bacteria. - Peer J 3: e1291.

[27] Stajković-Srbinović, O., Delić, D., Kuzmanović, D., Protić, N., Rasulić, N., KneževićVukčević, J. (2014): Growth and nutrient uptake in oat and barley plants as affected by rhizobacteria. - Rom. Biotechnol. Lett 19: 9429-9436.

[28] Ullah, S., Qureshi, M. A., Ali, M. A., Mujeeb, F., Yasin, S. (2017): Comparative potential of Rhizobium species for the growth promotion of sunflower (Helianthus annuus L.). Eurasian Journal of Soil Science 6: 189-196.

[29] Wang, Y., Wei, S., Wang, J., Su, X., Suo, B., Qin, F., Zhao, H. (2018): Exogenous application of 5-aminolevulinic acid on wheat seedlings under drought stress enhances the transcription of psbA and psbD genes and improves photosynthesis. - Brazilian Journal of Botany 41: 275-285.

[30] Yanni, Y. G., Rizk, R., Corich, V., Squartini, A., Ninke, K., Philip-Hollingsworth, S., Orgambide, G., De Bruijn, F., Stoltzfus, J., Buckley, D. (1997): Natural Endophytic Association between Rhizobium Leguminosarum bv. trifolii and Rice Roots and Assessment of its Potential to Promote Rice Growth. - In: Ladha, J. K. et al. (eds.) Opportunities for Biological Nitrogen Fixation in Rice and Other Non-Legumes. Springer, Dordrecht, pp. 99-114.

[31] Ye, Q., Zhang, H., Wei, H., Zhang, Y., Wang, B.-F., Xia, K., Huo, Z.-Y., Dai, Q.-G., Xu, K. (2005): Effects of nitrogen fertilizer on nitrogen use efficiency and yield of rice under different soil conditions. - Acta Agronomica Sinica 31: 1422. 
[32] Yildirim, E., Karlidag, H., Turan, M., Dursun, A., Goktepe, F. (2011): Growth, nutrient uptake, and yield promotion of broccoli by plant growth promoting rhizobacteria with manure. - HortScience 46: 932-936.

[33] Zahir, Z. A., Yasin, H., Naveed, M., Anjum, M., Khalid, M. (2010): L-tryptophan application enhances the effectiveness of rhizobium inoculation for improving growth and yield of mungbean (Vigna radiata (L.) Wilczek). - Pak J Bot 42: 1771-1780. 